\title{
A review on mobility models in disaster area scenario
}

\author{
Nor Aida Mahiddin*, Fatin Fazain Mohd Affandi and Zarina Mohamad \\ Faculty of Informatics and Computing, Universiti Sultan Zainal Abidin (UniSZA), Terengganu, Malaysia
}

Received: 21-April-2021; Revised: 06-July-2021; Accepted: 15-July-2021

(C)2021 Nor Aida Mahiddin et al. This is an open access article distributed under the Creative Commons Attribution (CC BY) License, which permits unrestricted use, distribution, and reproduction in any medium, provided the original work is properly cited.

\begin{abstract}
Communication network plays a big part for us in our lives. It is needed to perform daily tasks, access information and communicate each other anytime, anywhere and from any device. Nowadays, the communication network is a priority when it comes to a disaster scenario such as earthquakes, typhoons, tsunamis etc. The fixed communication network may be partially or fully destroyed or may be overloaded due to the aftermath of the disaster. It is crucial for rescue teams to establish a disaster recovery network for them to communicate with each other during their Search and Rescue (SAR) operations and mission critical. The disaster recovery network must be established within a short period to ensure the smooth operation of the rescue teams. Mobile Ad-Hoc Network (MANET) is a favourable approach for recovering the communication network as it can be deployed rapidly after the disaster rather than fixed communication network. MANET is an infrastructure-less network that can be deployed instantly and maintained easily. MANET can be used to address the issue of increasing communication requests, especially for data, speech, and video stream transmission. Due to limitations on scalability, repeatability, speed and cost, software simulations are often chosen instead of field-test experiments to verify the characteristics of designated topology control and protocols used in MANET for the disaster area scenario. The behaviour of the protocols used in MANET is highly affected by nodes' mobility model. The mobility model shows the nodes' movement and should be able to resemble the real-life situation for the designated scenario. Most of existing mobility models, such as random-based movements show unrealistic movement in concerns with the rescue teams' movement as they will not move randomly during their SAR operations. Instead, their movements are influenced by existing obstacles such as walls, trees and others. This paper reviews the existing mobility models used for investigating the movement of the rescue entities in the disaster area scenario. Some of other resilient disaster communication networks aside from MANET and MANET simulation tools were also reviewed. The main aim of this paper is to find the ideal mobility model that can realistically describe the movement of the rescue entities in the disaster area scenario. A comparative analysis, which includes the approaches and limitations on the related works was presented. By the end of this paper, a conclusion is drawn and suggestions aspects for future researches were stated.
\end{abstract}

\section{Keywords}

Disaster area network, MANET, Mobility model, Post-disaster, Node mobility, Network performance.

\section{Introduction}

Disaster struck does not announce itself and people usually caught with the ad hoc situation. Disaster is divided into two types which are natural disasters and man-made dis asters. Natural disasters happen because of a natural phenomenon or process such as earthquakes, tsunamis, typhoons and others. Manmade disasters happen as a consequence of technological or human hazards such train accident, traffic collision, aviation incident (plane crash), structural collapse and others. Such disaster struck events may cause fixed network infrastructure to be partially or fully-destroyed.

\footnotetext{
*Author for correspondence
}

The deployment of the fixed network infrastructure will be almost impossible to be re-established and recovered within a short time, especially in remote area where one had never existed.

During the disaster struck, two entities would be existed which are victims and rescue teams like firefighters, police, volunteers and medical teams. The communication network is vital, especially after the disaster struck as the rescue teams need to coordinate the Search and Rescue (SAR) operations and mission critical. The real-life situation can remain unknown to the rescue teams involved in the SAR operations or it can be totally different from what it was before the disaster due to the damages. Subsequently, the exchange of data on the latest condition at the disaster area plays a big part and is crucial to save lives and 
ease possible damages [1]. Network connectivity and data is a challenging problem, especially in Public Protection and Disaster Relief (PPDR) due to the dynamic mobility and harsh environment. Historical data show that the communication demand often experiences extreme increment especially after the disaster struck. To cope with various of rescue operations, the network can be efficiently adapted, making the loss of life and possession to be minimized as much as possible. An alternative way needs to be deployed to recover the communication network in the disaster area.

Mobile Ad-Hoc Network (MANET) is a type of wireless ad-hoc networks where every device able to travel independently in any way. MANET is an infrastructure-less network and a self-aligning pointing to support the movement of devices. MANET is easy to maintain due to its self-configured, selfrepairing and self-recovery network [2, 3]. MANET characteristics of being decentralize and infrastructure-less network allows users to establish a dynamically reconfigurable wireless network with the absence of a fixed infrastructure network.

Figure 1 shows the operation of MANET on how nodes (users) communicate with each other even without the present of the fixed infrastructure network. If the destination node is outside the source range, the neighbour node will act as a relay to forward the message until it reaches to the destination [2]. However, the network is a stand-alone. People usually carry on their mobile devices with them anywhere and anytime. MANET can join the mobile devices even when the fixed infrastructure is absent as their mobile devices are equipped with the wireless technologies such as Bluetooth and Wireless Fibre (WiFi), hence MANET can be easily formed.

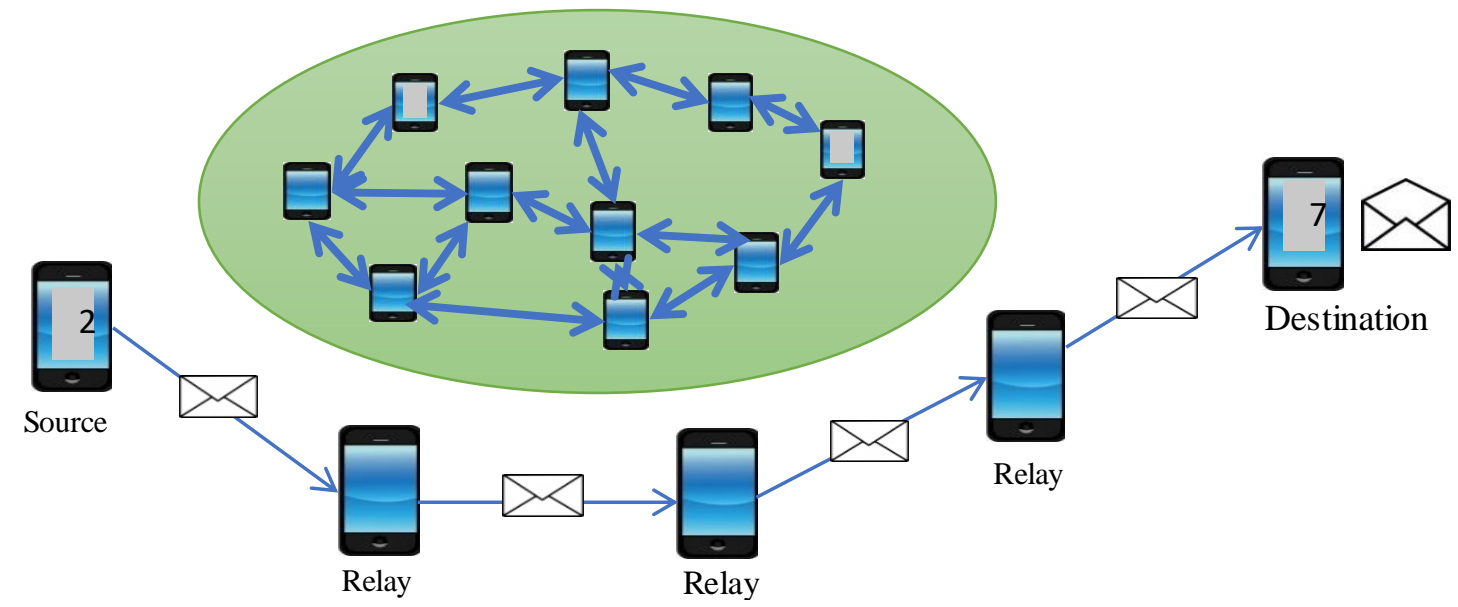

Figure 1 MANET operations [3]

MANET can be considered as a promising solution, especially in an unfavourable conditions such as disaster response and recovery where fixed infrastructure is unavailable due to the aftermath of the disaster [4]. The communication network can be recovered within a short time, making delays and errors in SAR operations and mission critical to be minimized. Thus, the MANET can be considered as one of the best approach for SAR operations due to its rapid deployment, making the rescue teams to immediately respond to the victims call for help upon receiving $[4,5]$.

The objectives to focus the current aspects in this area are as under:

1. To report and study the existing mobility models used in the disaster area scenario.
2. To discuss the requirements of designing a realistic mobility model based on the movement of the rescue entities in the disaster area scenario.

3. To present a comparative analysis of the related works.

\section{Literature reviews}

2.1 Mobility models in disaster area scenario

For the past years, there are some works that evaluated the performance of the nodes in disaster area scenarios by adapting the existing and/or proposing a new mobility model when performing simulative analysis. The mobility model produces the movement traces of nodes and can be generated by using software like Bonnmotion [6]. The previous works mostly evaluated the network performance of routing protocols and algorithm schemes under certain mobility models in a 
case of the dis aster area scenario, tactical area network or multi-hop network.

In 2004 Aschenbruck et al. [1] proposed a new mobility model, namely, Disaster Area (DA) mobility model which is based on the tactical issues of civil protection where the concept of room separation is introduced. The network performance was evaluated between the DA model, Gauss-Markov (GM) and Random Waypoint (RWP) model by varying number of nodes and its velocity. However, certain aspects are not yet feasible. For example, group mobility is ignored, and the RWP model determines the mobility of agents within each sub-area.

In 2007 Boldrini et al. [7] proposed Home-cell Community-based Mobility Model (HCMM) for opportunistic networks. Two properties which are contact duration and intercontact time were analysed to demonstrate that the proposed model can generate realistic movement patterns for opportunistic networks. The contact duration was defined as the time period during which any two devices are within radio range of one another. Meanwhile, intercontact time was defined as the time interval between two consecutive node contacts. The proposed model, The HCMM retains the socially conscious characteristics of the Community-based Mobility Model (CMM). Nonetheless, this paper does not evaluate performance on node mobility using network performance metrics such as throughput, Packet Delivery Fraction (PDF), Normalized Routing Load (NRL), overhead, and energy consumption. As a result, the proposed model's efficiency in performing SAR operations has yet to be determined in the disaster area scenario.

In 2007 Nelson et al. [8] proposed a gravity-based model known as Event and Role-based Mobility Model (ERMM) that implements "Flee" and "Approach" action. The authors compared changes in the network topology. Numerous topologies were generated, and ten sets of simulation results from the ERMM and Random Walk (RW) model are presented. However, the authors' interest in this work was limited to the mobility patterns of objects in a disaster scenario and their topological implications for the network graph. Communication between nodes was not considered. Thus, it is necess ary to analyse the effects of various parameters in communication and routing in disaster scenarios in order to determine their performance in terms of node mobility.

In 2009, Rollo and Komenda [9] proposed Tactical Networks Mobility Model (TNMM). Basic characteristics of the mobility model such as node spatial distribution and average node degree were analysed between the TNMM model and the RWP model. The TNMM is goal-oriented and compatible with a range of mobile units as well as stationary wireless sensors. Depending on the created objectives, the nodes can form temporary groups and move in formations throughout the area, simulating the behaviour of real-world tactical units. However, the authors did not conduct a comprehensive study of network efficiency in terms of node mobility. It is important to understand the model's performance under adverse conditions such as obstacles and signal interference during the SAR operations. Therefore, how routing overhead may affect the energy consumption, as it is one of the factors that cause nodes to communicate for an extended period of time prior to the physical network being installed succes sfully.

Papageorgiou et al. [10] proposed architecture for mission-critical MANETs namely, Mission Critical Mobility Model (MCMM). To investigate the properties of MCMM, a simulation was carried out extensively, demonstrating the distinctions between the MCMM, Human Obstacle Mobility (HUMO), Obstacle Mobility (OM), and the RWP models. Properties such as resulting network connectivity and impact on a MANET's efficiency are observed. It is concluded that both in the MCMM and the HUMO models, the nodes traverse the entire accessible space, (network area), while in the OM model, the nodes traverse pathways. In the case of the RWP model, the existence of constraints is neglected. Even so, harsh conditions with insufficient power make it impossible for the nodes to interact if other efficiency measurements such as energy consumption and overhead are not being considered.

To depict the realism of the rescue teams' displacements in the case of action in a disaster area scenario. Pomportes et al. [11] proposed Composite Mobility (CoM) model where a few models are being incorporated. Various aspects of the proposed model have been evaluated and compared to the RWP, Reference Point Group Mobility (RPGM) and Levywalk models. Although the evaluation of the proposed model showed that it keeps the realism, the authors stated that there is still a space of elements to be considered for improvement such as modelling a model on a macroscopic scale. The performance of the CoM model can be evaluated in terms of the network performance metrics to see how well the model can efficiently improve the communication of the rescue 
teams and its energy consumption as it is crucial to maintain the network communication as long as possible.

In 2011 Reina et al. [12] presented the comparative evaluation of MANETs routing protocols which were Ad-hoc On-demand Distance Vector (AODV), Adhoc On-demand Multipath Distance Vector (AOMDV) and Dynamic Source Routing (DSR) under realistic disaster scenarios. The DA model has been used as the mobility model and some performance metrics such as throughput, PDF, NRL and average End-to-End Delay (E2E) has been considered in the comparison of the routing protocols. As a result, AODV outperforms AOMDV and DSR. However, the communication paths between nodes have a limited lifespan. Thus, other routing protocols should be considered to determine the suitability of alternative algorithms.

In 2012 Raffels berger and Hellwagner [13] evaluated the performance of several MANET routing protocols in the case of emergency response scenario. The DA model has been used to simulate the movements of the first responder in a hybrid indoor/outdoor environment. AODV, Optimized Link State Routing (OLSR), Better Approach to Mobile Ad-hoc Network (BATMAN) and Dynamic MANET on-demand (DYMO) are selected as the routing protocols used and their performance are evaluated in terms of PDR, average PDR and packet delivery delay. Results showed that the nodes have diverse connectivity characteristics which led to increment in the packet loss rate. Some nodes are intermittently connected, resulting a higher packet loss.

In 2013 Conceição and Curado [14] proposed a new mobility model based on force vector, namely Human Behavior for Disaster Areas (HBDA), in which it imitates the real movement of nodes in the search missions. The authors investigated the performance of the HBDA in terms of the density distribution of nodes, node degree, area coverage, topology changes and throughput. It is concluded that the HBDA model enables a more realistic simulation of the disaster scenarios rather than random-based movement decisions. However, the scalability of the network was not considered in this work. Thus, a network hierarchy must be created that allows the routing protocol to scale in order to simulate a large number of nodes.

Martín-Campillo et al. [15] presented an analysis of the performance of the opportunistic routing in an emergency scenario by using the DA model. The emergency scenario's characteristics are analysed to determine their effect on the routing method's performance in terms of suitability for various performance requirements such as delivery rate and lifetime. In prolonged emergency scenarios involving a dense network of nodes or a large number of messages, an energy-efficient forwarding method is required to avoid depleting the node's battery. As a result, communication between nodes can continue for a longer period of time despite the harsh environment.

Reina et al. [16], proposed an adaptive broadcasting scheme based on topological conditions with the aim to improve the connectivity in the disaster scenarios. Through simulations, the DA model is used to depict the realis tic node movement and validate the proposed approach in terms of reachability and Save ReBroadcast (SRB). This approach considered both the tactical movements of the rescue teams and the communication flows between them in order to achieve an optimal design. The optimal probabilistic scheme's performance can be compared to that of other existing broadcasting schemes in terms of energy efficiency and lifetime despite the possibility of obstacles and signal interference in the real-life situation of disaster scenario.

Reina et al. [17], also conducted a performance comparison of MANETs routing protocols, AODV, AOMDV, and DSR, using the same mobility model. The difference between this work and the previous work [12] is that this work evaluates the routing protocol's performance in terms of dropped packets and hop count in addition to throughput, PDF, NRL, and E2E. According to the simulation results, AODV produces the optimal routing metrics. Meanwhile, AOMDV may be a viable option if end-to-end Quality of Service (QoS) is a concern, provided the environment is not particularly noisy. Nonetheless, specific routing protocols for rescue teams operating in disaster areas are required to address the issue of difficult conditions and limited connectivity, as demonstrated by real-life situation of disaster scenarios.

In 2014 Ebenezer [18] proposed Large Scale Disaster Mobility Model (LSDMM) to address the concerns on the unrealistic representation of complex real-world geographical constraints and the absence of a technique for path modelling in the absence of a known route. This approach enables the node to choose the combination of the nearest cell and the cell with the highest node density with a high probability. Through the simulative analysis, the simulation area is 
divided into different obstacle regions based on their density, which are dense, sparse and obstacle free. The LSDMM takes not only geographic constraints into account, but also spatial and temporal dependencies. Degree of spatialdependence is around 1 for LSDMM, which is higher than RWPA and DA models, whose values are negligible. The author only considered an average node degree and average link duration of the nodes and statistics are determined in relation to the transmission range. However, as the range expands, an increment in the overhead may occur, thus reduce the overall network capacity.

Reina et al. [19], also proposed a new probabilistic broadcast scheme based on similarity/dissimilarity metrics and integrated it into the existing DA model. Due to the probabilistic nature of the proposed approach, the results of each generation run for each individual in the population will be averaged out. Calculations of reachability, retransmissions, and delay were used to identify non-dominated solutions and generate new generations. However, the performance of other routing protocols, and optimization algorithms must be considered in order to develop a solution that is suitable for use in disasteraffected areas and accurately depicts the movement of rescue teams.

In 2015 Arbia et al. [20] evaluated the performance of different routing protocols, namely, OLSR Version 2 (OLSRv2), AODV Version 2 (AODVv2), Greedy Parameter Stateless Routing (GPSR) and Directed Diffusion (DD) while using different type of communication technologies. The authors studied the network performance in an urban critical and emergency scenario. The simulative analys is has been conducted using the DA model and performance metrics such as Packet Reception Rate (PRR), packet delay and energy consumption have been considered. Results showed that $\mathrm{WiFi}$ technologies gave better performance with respect to the PRR and energy consumption while Wireless Body Area Networks (WBAN) performs better in packet delay. If the location information is available, GPSR with WiFi outperforms other routing protocols. In contrary, if the location information is unavailable, DD routing protocol with WBAN gives better performance.

Meanwhile, in $2016 \mathrm{~W}$ ang et al. [21] proposed a novel mobility model based on Disaster Area Wireless Networks (DAWNs) namely Catastrophic Intensitybased Rescue Mobility Model (CIBRMM). The authors evaluated the performance between the CIBRMM and Traditional Mobility Model (TMM) in terms of the rescue time with different number of affected areas and Catastrophic Intensity (CI). Nonetheless, the authors neglected to consider the performance of the routing protocols used during the rescue process in this work. The network performance metrics such as throughput, PDF, overhead, and NRL must be evaluated by simulating some real-life situation in order to analyse the communication network's efficiency during the SAR operations.

In the same year, a synthetic mobility model proposed by Gondaliya and Atiquzzaman [22] namely Rolebased 3-Tier Mobility Model (RTTMM). Through this paper, the authors analysed the RTTMM with the ERM model in terms of average device degree, maximum device degree and clustering coefficient. The RTTMM is found to be more effective and more applicable in the disaster area scenario than ERM. The authors also evaluated the performance of the Delay Tolerant Network (DTN) routing protocols under RTTMM in terms of delivery ratio, latency, average overhead ratio and cost per message. Results showed that MaxProp routing protocol outperforms other DTN routing protocols in terms of delivery ratio, but having decrement with the message size beside having high latency, overhead ratio and cost per message. Instead, Encounter Based Routing (EBR) protocol showed the next best performance in terms of delivery ratio with the lowest latency, stable overhead ratio and cost per message.

In 2017 Stute et al. [23] proposed Natural Disaster (ND) model which use reverse engineering approach based on 126 knowledge experts for the large-scale natural disasters. The disadvantages in this work, are the differences in the nodes' speed that will act as transport nodes are not being considered. In the reallife situation, there will be some nodes that are using the vehicles to transport the victims from the disaster area. They would join and/or leave the group during the operations. The speed of the transport nodes is different as the vehicles are involved during the SAR operations. Therefore, the scalability of the current simulator must be increased to support simulations with significantly more nodes. A realistic communication model encompassing all users in a disaster scenario needs to be considered and evaluate the performance in order to determine the communication network's efficiency during the SAR operations.

Sani et al. [24] attempted to study the Transmission Control Protocol (TCP) performance in MANET routing protocols. By using the DA model in the 
simulation experiment, the authors considered PDR, average throughput and average E2E delay as the performance metrics for the performance evaluation. For the mobility model, the routing protocols are evaluated against different traffic scenario and node density. Results showed that AOMDV outperforms DSR and ZRP in terms of throughput and E2E delay. However, DSR yields better in terms of PDR while Zone Routing Protocol (ZRP) gives the worst performance compared to others.

Al-Shehri et al. [25] presented a comprehensive comparison between the tactical and commercial MANETs on performance and design characteristics. The simulation was carried out under three different mobility models which are RPGM, RWP and Manhattan-grid model. Results showed that the RPGM model with two-ray ground model produces the most accurate performance predictions for mobile tactical networks.

In 2018 Kim et al. [26] proposed a novel routing protocol for Unmanned Aerial Vehicle (UAV) relayed tactical MANET, where different features from the typical MANET was shown. The authors proposed two scenarios to be used for the network congestion and link breakage. Through this paper, the authors have discussed on operating procedure and further is sue for admission control for each of the scenarios. The impact of the UAV relay has been evaluated with concerns to PDR and E2E delay under the RPGM model.

In $2020 \mathrm{Kim}$ et al. [27] proposed a MANET locationbased routing scheme by applying dual channels known as sub-GHz and $2.4 \mathrm{GHz}$ channels for the indoor disaster scenario. This paper studied and proposed a new scheme with concerns to the firefighter communications as the indoor disaster environment were not being considered in the previous researches. Performance evaluation has been conducted under the RWP model and analysed in terms of PDR, end-to-end E2E delay and initial routing table configuration time. Results showed that the Dual-Channel-based Routing (DCR) outperforms than the other two routing protocols which were OLSR-mod and Destination-Sequenced DistanceVector (DSDV)-mod with respect to the metrics considered and scalability.

Younes and Albalawi [28] proposed an analytical model for the link and route lifetime in the mobile multi-hop networks. The RWP model has been used in the simulation by varying different network characteristics. The proposed analytical model was validated by comparing the analytical and simulation results. However, as the transmission range increase, the interference from the neighbour nodes increased, causing decrement to the network throughput.

\subsection{Disaster resilient communication networks}

For the past years, there has been improvements made by the researchers in terms of the disaster resilient communication networks. The improvements are made to ensure that the communication can be established successfully within a short time, despite having such scenario such as during the disaster struck. During the SAR operations, it is crucial to have a good communication network, which is robust, reliable and fast-deployment. Good communication networks will increase the performance of the mobility as the information can be delivered and received well by the rescue teams. Thus, the SAR operations can be conducted smoothly even in the dis aster area scenario. 2.2.1Movable and deployable resource units (MDRUs) A new vision of disaster resilient networking was discovered by Sakano et al. [29] which was based on MDRUs. The MDRU is known as a transportable unit which is equipped with general physical infrastructures to deliver the information and communication services. It supports both communication and information processing operations, which can be rapidly transported and instantly deployed upon arrives at the disaster area.

The MDRU composes of the concept of movable and quickly deployable resource units [29]. Besides, the MDRU deployment is facilitated in an easily-handled manner. Once the MDRU is setup, it will create the network access which is $\mathrm{WiFi}$ and Fixed Wireless Access (FWA). The network established will be hybrid networks consisting of mesh and ad hoc networks. Service providers can establish dedicated virtual networks to its covered users by offering multiple network services via adaptation of network slicing technology [30]. Thus, the cooperation between MDRUs was proven to cover the disaster areas dynamically.

Sakano et al. [31] also proposed a van-type resource unit which is compact, and agile, assuring its robustness and reliability of the system. The equipment inside the van-type MDRU is modularized to be portable equipment. The field-tests experiments have been conducted and the results showed that the MDRU-based technology has a large potential in achieving effective disaster response. 
MDRU is easy to configure as it can be installed promptly, cutting the installation time and support large coverage. It is one of the ideal ways in terms of network coverage as the service can even reach even in the isolated places [31]. However, this approach is not commonly used if we are to evaluate its performance in terms of the node's mobility since it is conducted through the field-test experiments making it time consuming, large scalability and high costing. 2.2.2Long range (LoRa) - based technology

LoRa Alliance proposed a low-powered Wide Area Network (WAN) technology, which aims at the wireless devices that link to local, territorial or national networks. It focuses on securing two-way communication which is mobility and localization services through star topology. The gateway will serve as a transparent bridge between end-devices and network server on the back-end via IP networks [32].

LoRa requires a license from Semtech company and implementation of specific hardware, and it is not dependent on Low Power Wide Area Network (LoRaWAN) and thus can be used in a device-todevice fashion [33].

While LoRa devices and wireless radio frequency technology is defined as a long-range, low power wireless platform that has emerged a critical technology in the world of Internet of Things (IoT), LoRaWAN is showing its capability in exploiting transmitted packages to calculate the current position without utilizing the current Global Positioning System (GPS) or Global System for Mobile (GSM) communication [34].

The combination of these two technologies results precise location of remote area and indoor use cases prediction solution in an efficient, flexible and economical way where the cellular and $\mathrm{WiFi}$ or Bluetooth Low Energy (BLE) are ineffective. LoRaWAN is a powerful technology, especially in determining the geolocation of a physical entity, where its long-range capabilities can be reached up to $15 \mathrm{~km}$ due to its sensitivity of the receivers. LoRaWAN is good at minimalize its energy consumption as it utilizes low power technology of LoRa to calculate the geolocation rather than GPS or GSM.

Sciullo et al. [35] has proposed a LORA-based mobile emergency management system known as LOCATE. LOCATE is a novel phone-based Emergency Communication System (ECS) that enables longrange communication between victims and rescue teams in critical environments lacking $3 / 4 \mathrm{G}$ cellular connectivity. It enables multi-hop distribution of alert messages that contain only the most critical information about the requester's location and emergency type. The system is composed of a mobile application that communicates with a LoRa device BLE. The users will then generate the message alert via the LOCATE system, and it will be re-broadcast by their peers until it reaches the rescue personnel that capable of handling the emergency. The performance was evaluated using OMNeT++ simulations, utilising the dis semination protocol's capability to dis tribute the emergency request across large-scale scenarios.

A method for facilitating LoRa device-to-device communication through smartphones in the disaster area scenario is proposed in [33].

They proposed developing their own firmware for a low-cost LoRa device. They demonstrated two applications that utilize the proposed firmware's flexibility. They have demonstrated a novel device-todevice LoRa-based chat application for mobile users on Android and iOS, as well as a console-based interface for traditional computer users. Besides, they contributed by demonstrating how other infrastructure-free technologies can gain benefits from their approach through integration with DelayTolerant Networking (DTN7) software.

Although the approach eases the users, especially in the world of the IoT, however, it is quite complicated to understand how it actually works and it might take a little time before it can be properly implemented. 2.2.3Flying Ad-Hoc networks (FANETs)

A Flying Ad-hoc Network (FANET) is a network comprised of a collection of small UAVs that communicate ad hoc in order to accomplish high-level objectives. The primary characteristics of FANETs that stand out are their mobility, lack of central control, self-organizing nature, and ad hoc nature. These characteristics of FANETs make them well-suited for disaster areas where physical communication infrastructure has been destroyed or is unavailable. It is rapidly deployable, adaptable, self-configurable, and has a low operating cost network. However, establishing a reliable and a robust communication system with UAVs is a significant challenge because it requires a suitable communication architecture and routing protocols that can be configured with highly dynamic flying nodes.

Khan et al. [36], presented a suitable communication architecture for FANETs and an overview of various routing protocols. The authors concluded in their 
paper that a multi-layer UAV ad hoc network would be more suitable for use in FANETs. Furthermore, some researchers proposed the use of UAVs in conjunction with MANETs and LoRa technology to establish a reliable and resilient communication system.

Nowadays, Wireless Mesh Network (WMN) has got the attention and thoroughly investigated in a variety of fields, including architecture, implementation and protocol creation. Multi-Radio Multi-Channel (MRMC) has been acknowledged by many organizations, especially in rural network, battlefields and natural disasters, where the rapid communication network is needed for implementation. WMN composes of mesh nodes from gateways, routers and clients [37].

Molla et al. [38] proposed connectivity via multiple Radio Access Networks (RANs) carried by a Wireless Multi-Hop Network (WMHN) that combines existing Flying Mesh Networks (FMNs) with additional opportunistic MANETs created by the rescuers. GSM, WiFi and LoRa technologies are chosen due to their native support by smartphones. It is then being implemented by a single embedded Software Defined Radio (SDR)-based making it a reliable and resilient wireless network for SAR operations. To improve the connectivity and coverage for the rescuers or survivors, the authors proposed using a drone or balloon to form the FMN as the GSM base station.

These solutions do not seek to substitute the existing solutions, but rather to provide a complement to them [38]. Due to the fact that the smartphones support GSM, WiFi, and in some cases, LoRa, they can leverage the WMHN to connect to the command post via the RANs, thereby resolving the connectivity issue.

Solpico et al. [39] proposed an application of VehicleHub (V-Hub) standard for disaster resilient communication by using LoRa beacons, mobile cloud, UAVs and DTN. The V-Hub standard is intended to leverage Vehicle-To-Everything (V2X) connectivity to create an information and communication system in the disaster area scenarios. The beacon and data aggregator communicate via LoRa to allow survivors and rescuers to be discovered, detected, and communicate. The aggregators may be carried by hand or mounted on vehicles as part of the rescue kit.

Therefore, it is suitable for use as a payload for a small Unmanned Aerial Vehicle (UAV). The UAV will then perform long-range surveillance scouting operations as part of the initial wave. To simplify, the survivors and the rescuers will transmit their data via LoRa beacons to an aggregator mounted on a flying UAV. After landing in the mobile command centre, the UAV uses the DTN to transfer aggregated data to the information kiosks and mobile cloud servers. It allows communication in the disaster scenario, des pite having damaged communication infrastructure. All of this allows the rescue mission planners, policymakers, and decision makers to make more informed and timely decisions in the face of disrupted communication lines [39].

Qiu et al. [40] proposed an integrated air-ground heterogeneous network architecture to fully capitalize on the potential advantages of different types of UAVs. High-Altitude Platforms (HAPs), LowAltitude Platforms (LAPs) and ground segments is integrated to improve the coverage and capacity for underserved scenarios. Wide coverage, especially in rural and remote areas is achieved through utilization of the HAPs layer, while local network optimization mainly for temporary or emergency scenarios is achieved by utilizing the LAPs layer. The ground layer is utilized for serving the urban areas. The authors highlight that each of the layers have their own role and act as a complementary towards each other via integration approach.

However, the proposed solution in [40] only focuses on providing additional capacity and wide coverage for the designated areas without taking energy consumption into account. Thus, in the future, energy efficiency needs to be considered especially in the disaster areas as we need to ensure the communication between the rescue teams can last longer as possible before the fixed infrastructure can be fully recovered.

Overall, FANETs really have their own characteristics that provide a more resilient disaster networking especially during the disaster struck. However, it is a challenging issue for the UAV in terms of their flight time and how it can affect the performance of the mobility nodes. Besides, it is quite costing to provide the UAVs to cover a large-scale area scenario.

\section{Methodology}

Data analysis

This paper has reviewed the existing mobility models in the related areas where various approaches have been proposed and evaluated under different mobility models to solve different issues while considering different performance metrics. The complete criteria, 
Nor Aida Mahiddin et al.

details and sources of each paper reviewed can be

found from Table 1, Figure 2 and Figure 3.

Table 1 Papers collection criteria

\begin{tabular}{|c|c|c|c|c|}
\hline \multirow[t]{2}{*}{ Reference } & \multirow[t]{2}{*}{ Year } & \multirow[t]{2}{*}{ Source } & \multicolumn{2}{|l|}{ Criteria } \\
\hline & & & Inclusion & Exclusion \\
\hline Aschenbruck et al. [1] & 2004 & ITL & $\begin{array}{l}\text { Human mobility in MANET } \\
\text { disaster area. }\end{array}$ & $\begin{array}{l}\text { Difference in number of nodes } \\
\text { and speed of nodes. }\end{array}$ \\
\hline Boldrini et al. [7] & 2007 & IEEE & Realistic movement patterns. & Opportunistic network. \\
\hline Nelson et al. [8] & 2007 & MOBICOM & $\begin{array}{l}\text { Gravity-based model in disaster } \\
\text { area scenarios. }\end{array}$ & Topological implications. \\
\hline Rollo and Komenda [9] & 2009 & Springer & $\begin{array}{l}\text { Mobility model in tactical } \\
\text { network. }\end{array}$ & Topology control. \\
\hline Papageorgiou et al. [10] & 2009 & $\mathrm{ACM}$ & Mission critical MANET. & $\begin{array}{l}\text { Lack of } \\
\text { measurements. }\end{array}$ \\
\hline Pomportes et al. [11] & 2010 & IEEE & $\begin{array}{l}\text { Rescue teams' displacement in } \\
\text { disaster area scenarios. }\end{array}$ & Scalability of network. \\
\hline Reina et al. [12] & 2011 & IEEE & $\begin{array}{l}\text { Performance of routing protocols } \\
\text { in disaster area scenarios. }\end{array}$ & Different routing protocols. \\
\hline $\begin{array}{ll}\text { Raffelsberger } & \text { and } \\
\text { Hellwagner [13] } & \end{array}$ & 2012 & IEEE & $\begin{array}{l}\text { Emergency response scenario/ } \\
\text { Disaster mobility model. }\end{array}$ & $\begin{array}{l}\text { Different of MANET routing } \\
\text { protocols. }\end{array}$ \\
\hline $\begin{array}{l}\text { Conceicao and Curado } \\
{[14]}\end{array}$ & 2013 & Springer & $\begin{array}{l}\text { Movement of node in search } \\
\text { missions. }\end{array}$ & Scalability of network. \\
\hline $\begin{array}{l}\text { Martini-Campillo et al. } \\
{[15]}\end{array}$ & 2013 & JNCA & $\begin{array}{l}\text { Movement of nodes in disaster } \\
\text { scenarios. }\end{array}$ & $\begin{array}{l}\text { Focus to opportunistic } \\
\text { networks. }\end{array}$ \\
\hline Reina et al. [16] & 2013 & IMIS & $\begin{array}{l}\text { A broadcasting scheme based on } \\
\text { topological conditions. }\end{array}$ & Focus to connectivity only. \\
\hline Reina et al. [17] & 2013 & Springer & $\begin{array}{l}\text { Performance of routing protocols } \\
\text { in disaster area scenarios. }\end{array}$ & Different routing protocols. \\
\hline Ebenezer [18] & 2014 & ICCIT & $\begin{array}{l}\text { Node movement in large scale } \\
\text { disaster. }\end{array}$ & Probabilistic approach. \\
\hline Reina et al. [19] & 2014 & Springer & $\begin{array}{l}\text { A broadcast scheme based on } \\
\text { similarity/dissimilarity metrics. }\end{array}$ & $\begin{array}{l}\text { Neglect other routing } \\
\text { protocols, and optimization } \\
\text { algorithms. }\end{array}$ \\
\hline Arbia et al. [20] & 2015 & IEEE & Tactical ad hoc networks. & $\begin{array}{l}\text { Different of routing protocols } \\
\text { and } \\
\text { technologies. }\end{array}$ \\
\hline Wang et al. [21] & 2016 & IEEE & $\begin{array}{l}\text { Mobility model in disaster area } \\
\text { scenario. }\end{array}$ & $\begin{array}{lll}\text { Disaster Area } & \text { Wireless } \\
\text { Networks (DAWNs). } & \\
\end{array}$ \\
\hline $\begin{array}{ll}\text { Gondaliya } & \text { and } \\
\text { Atiquzzaman [22] } & \\
\end{array}$ & 2016 & SCITEPRESS & $\begin{array}{l}\text { Mobility model in post-disaster } \\
\text { scenario. }\end{array}$ & $\begin{array}{l}\text { Different of delay tolerant } \\
\text { routing protocols. }\end{array}$ \\
\hline Stute et al. [23] & 2017 & ACM & $\begin{array}{l}\text { Mobility model for large scale } \\
\text { natural disaster. }\end{array}$ & Different roles and activities. \\
\hline Sani et al. [24] & 2017 & IEEE & Disaster recovery scenario. & $\begin{array}{l}\text { Different traffic scenario and } \\
\text { node density. }\end{array}$ \\
\hline Al-Shehri et al. [25] & 2017 & IEEE & Mobile tactical networks. & $\begin{array}{l}\text { Design characteristics of the } \\
\text { commercial and tactical } \\
\text { MANETs. }\end{array}$ \\
\hline Kim et al. [26] & 2018 & IEEE & Tactical ad hoc networks. & $\begin{array}{l}\text { Different scheme of routing } \\
\text { protocols. }\end{array}$ \\
\hline Kim et al. [27] & 2020 & IEEE & Firefighter communications. & $\begin{array}{l}\text { Different of MANET routing } \\
\text { protocols. }\end{array}$ \\
\hline $\begin{array}{l}\text { Younes and Albalawi } \\
\text { [28] }\end{array}$ & 2020 & IEEE & Mobile Multi-hop Network. & $\begin{array}{l}\text { Different } \\
\text { characteristics. }\end{array}$ \\
\hline
\end{tabular}




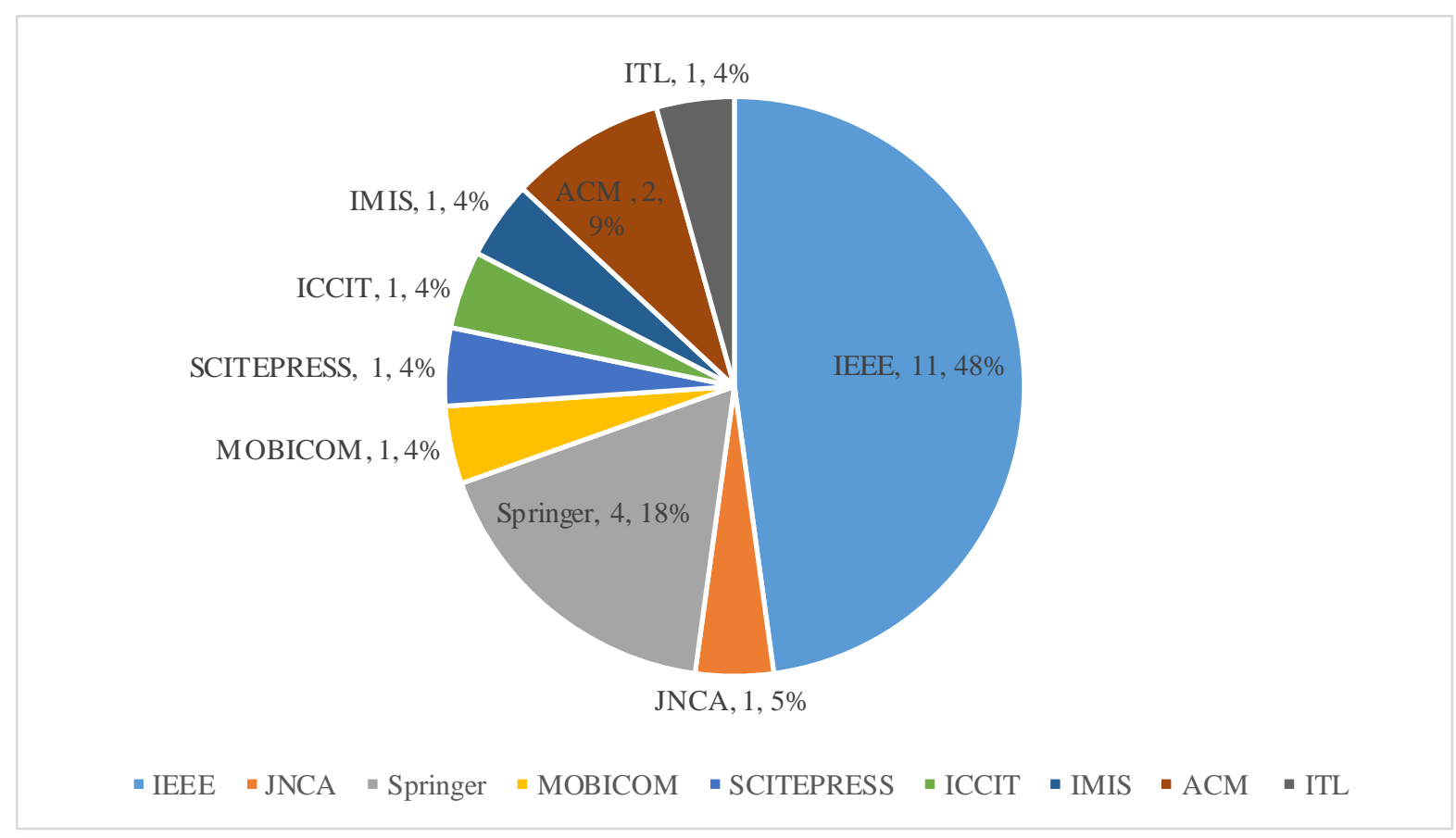

Figure 2 Sources of paper collection

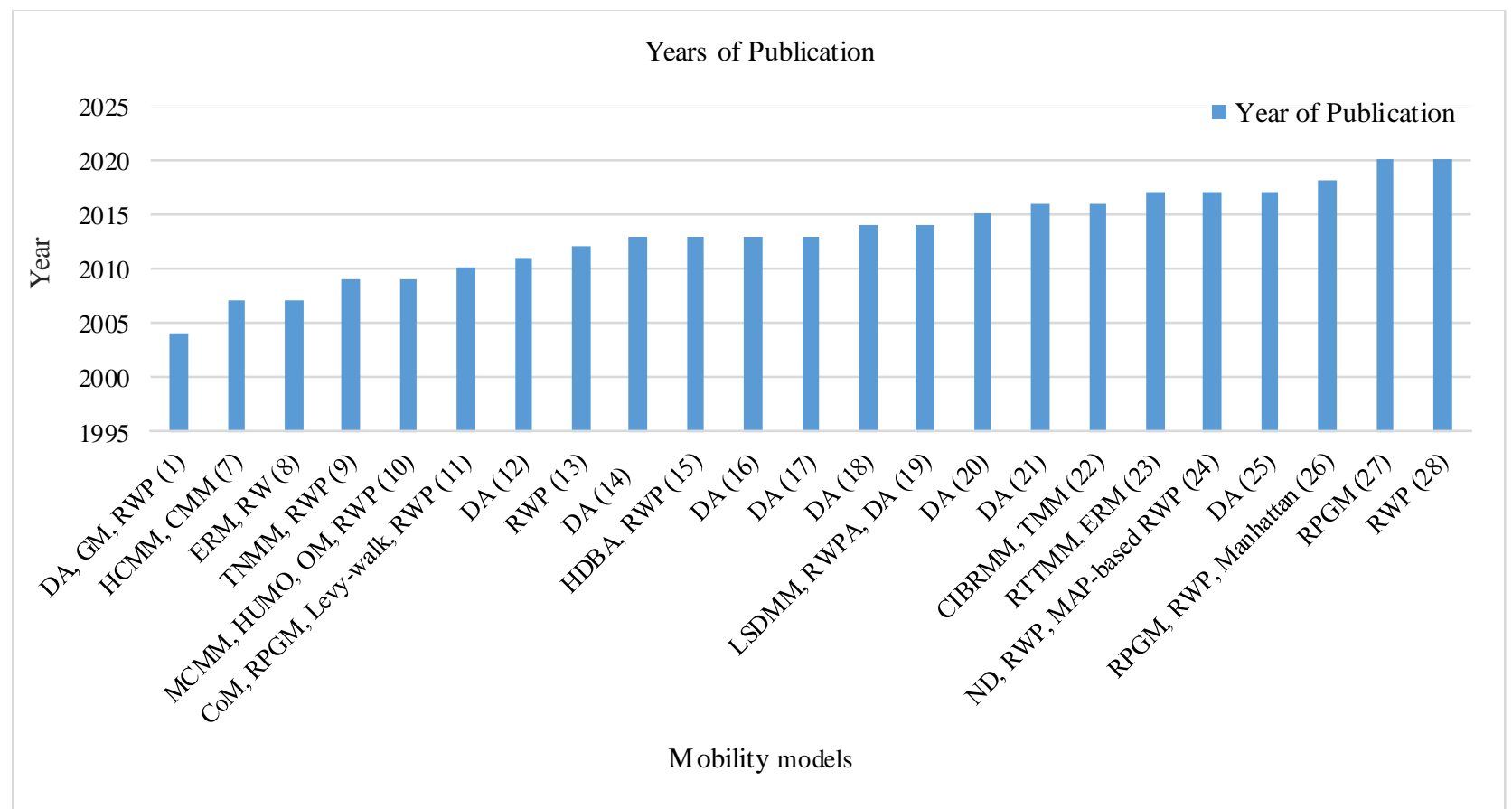

Figure 3 Years of paper publication

\section{Mobility model}

4.1 Mobility model and dependency

A mobility model is a collection of rules for generating paths for mobile entities. The mobility models are used in the software simulations to generate varies in the network topology as an outcome of node movement 857
[21]. The network topology in disaster areas always changes due to people moving around using the mobile devices, as the result of the node's mobility. Mobility features consist of node speed, direction and pause of nodes. 
During the disaster scenarios, the direction of nodes may change due to harsh environments such as the existence of obstacles. As a result, the mobility of nodes is affected and a device node may disconnect from a network [5]. Due to the node's mobility that need to be considered especially during the SAR operations where obstacles may exist, the process of determining the route may be difficult [22]. Hence, a suitable approach needs to be proposed in order to improve the network performance of the rescue teams in the case of disaster area scenarios.

Modelling the mobility of nodes can be challenging, as we must select appropriate algorithms and protocols for implementation. When simulating a MANET, it is critical to use a more realistic mobility model in order to accurately reflect the actual movement pattern of nodes. The mobility pattern will determine the node speed, direction, position and the way the nodes are moving within their range area that has been set [7]. Speed and direction changes will eventually happen, but within an acceptable time frame [23]. This behaviour has an effect on signal strength, battery life, bandwidth utilization and the result of the MANET's efficiency.

During the disaster, it is hard to assume the actual movement of nodes, victims' location and number of first responders working in the emergency as it is all different when in the real situation [24]. Each of the mobility models is being influenced by a certain dependency or restrictions. Generally, the mobility models can be classified according to the types of dependencies and constraints that are taken into account when creating the model. There are five types of dependencies which are random-based movement, temporal-based dependencies, spatial-based dependencies, geographical restrictions and hybrid characteristics. Figure 4 shows the summarization between the existing mobility models applied in the dis aster area and their dependencies.

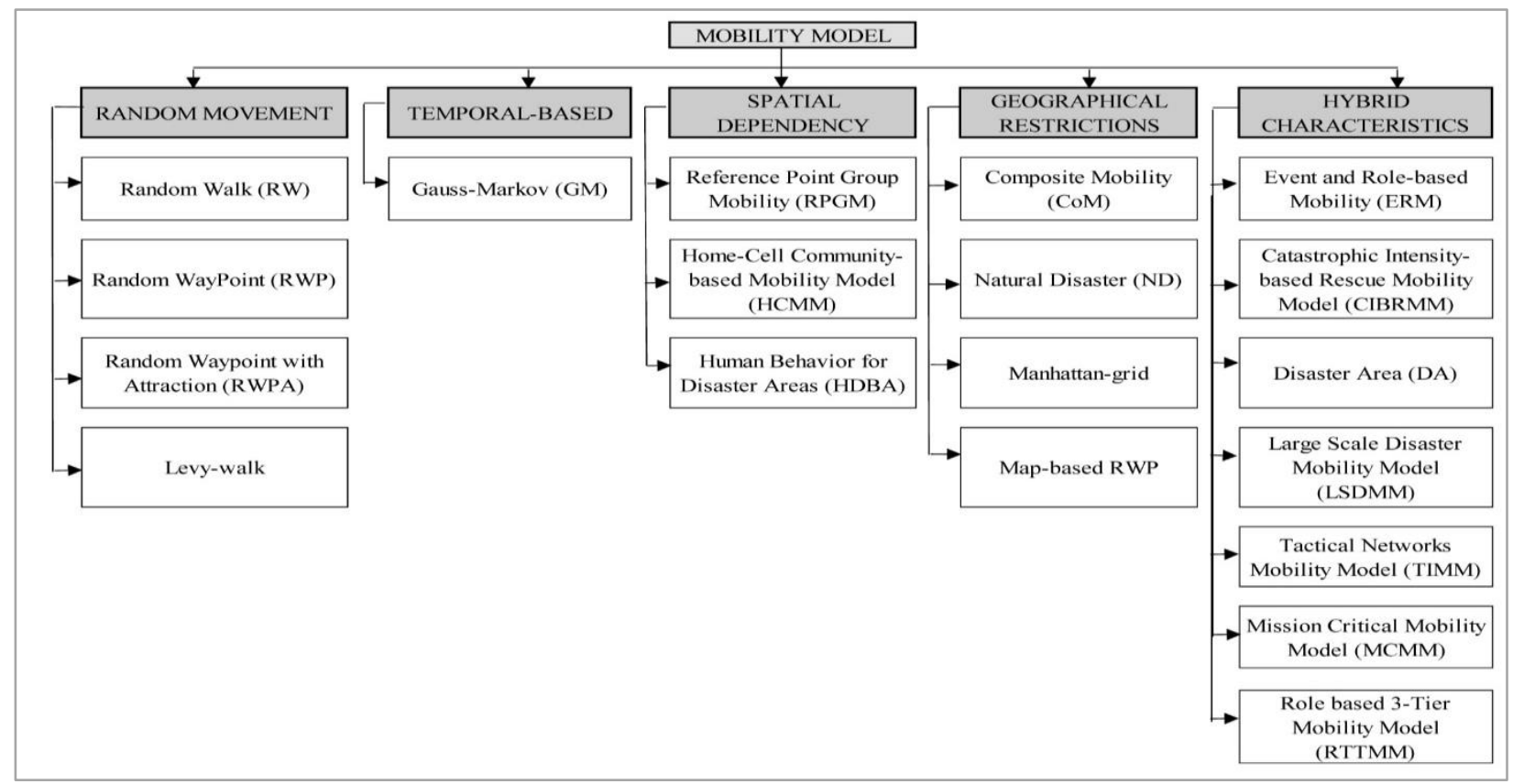

Figure 4 Mobility models and its dependencies

\subsubsection{Random-based movement}

There are neither dependencies nor any other restrictions modelled or nodes move randomly. Manaseer and Alawneh [41] stated that random-based movement is being unrealistic in representing the node movement, despite having difficulty to adapt to the special conditions and limitations that are present in the disaster areas. Aschenbruck et al. [5] explained that the random-based movement is indeed simple to 858 implement yet only optimal paths is realized in terms of requirement for modelling model in the disaster area. However, at least heterogeneous velocity may be incorporated quite easily.

4.1.1.1RW model

RW [42] is a mobility model in which a node travels in a random speed and direction from its current position to a new one. Originally, RW model was proposed to mimic the unpredictable behaviour of 
particles in physics. It is sometimes referred to as Brownian Motion. Because it is believed that some mobile nodes move in an unexpected manner, the RW model is proposed to imitate their movement behaviour. RW model is similar to RWP model as both models employ a high degree of randomness in their node movement. Consider that the RW model being a variant of the RWP model with no pause time. In RW model, on the other hand, the nodes alter their speed and direction at each time interval.

4.1.1.2RWP model

RWP [42] is a model that includes the pause time between changes in destination and speed. It is known as a simple stochastic model in which a node always moves towards a random destination by randomly choose a velocity from a uniform distribution (min_speed, max_speed). RWP model is one of the commonly used models for evaluating the network performance of the ad-hoc network because of its simplicity and easiness to model.

Although the model is used widely in the ad-hoc network environment, it is still unrealistic to represent the node movement in the disaster area scenario especially when evaluating the performance of the rescue teams. This is because, the movement patterns of the rescue teams should not move randomly but instead, move systematically as they will move according to their group leader during the SAR operations.

\subsubsection{RWPA model}

There are extensions to the RWP model that add attraction points to produce a more realistic nonequally distributed mobility [5]. The probability that a node will move towards the next destination by considering the area with or within an attraction point is larger than the other destination. The nodes visit some destinations more frequently than others. As a result, they continue to traverse the whole simulation area.

\subsubsection{Levy-Walk model}

Levy-Walk [43] is similar to RW model, but its walk time and pause time is more complex. Human walks of tens of kilometres in outdoor settings resemble a shortened version of Levy-Walk observed in animals. Levy-Walk model is a great model for simulating a variety of statistical patterns observed in human walking under certain conditions.

\subsubsection{Temporal-based}

Changes in nodes' speed and direction may suddenly happen if random-based movement model is used. While concerning many aspects such as acceleration and deceleration, it is still quite unrealistic. Thus, the model presented realizes such aspects by using the temporal dependencies. The temporal dependencies 859 describe that the current movements depend on the past ones [44]. The GM is one of the temporal-based mobility models in which a single tuning parameter is utilized to control the randomness degree in the mobility pattern. In other words, if the node travels outside the simulation area's boundaries, the node's direction is forced to reverse 180 degrees. As a result, the nodes are repositioned away from the simulation area's boundary [45]. The future velocity and direction (time interval $\mathrm{t}+1$ ) are dependent on the current values (time interval t). After the interval, each node's movement is altered [5].

4.1.3Spatial dependency

Spatial dependency describes that the movement of one node depends on the movement of surrounding units as there may be nodes that move together in groups [5].

4.1.3.1RPGM

RPGM [6] model is a widely used model for group mobility. Their movements are simulated by the model using the path taken by a logical centre. The movement of nodes within a group is determined by allocating a reference point to each node. The actual position of a node is computed by adding a random movement vector to the reference point's position. The absolute positions of the reference points vary according to the arbitrary mobility model. On the other hand, the relative positions of reference points within a group remain constant.

\subsubsection{HCMM}

HCMM [7] incorporates the concepts of the Community-based Mobility Model (CMM) as well as the concept of determining preferential locations where users spend the majority of their time. It is designed for opportunistic networks. According to the authors, the HCMM retains the socially conscious characteristics of the CMM.

4.1.3.3HBDA model

The HBDA is a force vector-based mobility model proposed by Conceicao and Curado [14] in which it imitates the real movement of the nodes during search missions. The optimal position between neighbours will be determined from the obtained list of in-range nodes. Meanwhile, a force vector is determined according to their distances to the neighbours. The resultant force vector will be normalized if the node's position is not optimized. Velocity between Min_Velocity and Max_Velocity will be generated randomly to compute a vector towards the next position and the process will be repeated until the end of the execution. The HDBA model enables a more realis tic simulation of the dis aster scenarios rather than random-based movement decisions. 


\subsubsection{Geographical restrictions}

It is unrealistic to predict that the nodes in all types of scenarios are allowed to travel the whole simulation area. Indeed, different approaches need to be taken to restrict the node movement to specified regions of the simulation area. Several models characterized with the geographical restrictions will be overviewed and discussed with concerns to the dis aster area scenarios. 4.1.4.1CoM model

The CoM [11] includes a realistic model of human displacement, team mobility and obstacle avoidance. RPGM is used to depict the group mobility while Levy Walk is replaced instead of RWP model to show a better realism. The Voronoi diagram is integrated as one of the model components in concern to the obstacle avoidance. Although the evaluation of the CoM showed that it keeps the realism, the authors stated that it still has a space for improvement such as modelling a model on a macroscopic scale.

4.1.4.2ND model

The ND model is proposed by Stute et al. [23] in which a reverse-engineering approach is used. It is based on 126 knowledge experts for the large-scale natural disasters. The ND model is a model in which mobile node movement is influenced by the different roles and activities in a specific scenario. However, the speed of transport nodes is not considered in their work and some improvements are needed such as applying a realistic communication model encompassing all users in a disaster area scenario.

4.1.4.3Manhattan-grid model

The Manhattan-grid model is a map-based approach mobility model where the simulation area is divided into squared blocks. The nodes are modelled as pedestrians that randomly distributed on the streets. They will keep moving on the vertices of the squares (streets) until they reach a corner. The nodes' velocity is changed over time [5].

4.1.4.4Map-based RWP

Map-based RWP [5] is a model in which node moves with random speed and direction following a map.

4.1.5Hybrid characteristics

In order to create a more realistic node movement considering a specific scenario, many researchers have proposed a hybrid mobility model. The hybrid model is the combination of some or all of the previous dependencies.

4.1.5.1ERM model

The ERM [8] is a gravity-based model in which a simplified law of physic in which "Flee" and "Approach" actions is defined. The ERM model allows the objects to react or respond to the existence of a variety of the disaster events, depending on the node's specific role.

\subsubsection{CIBRMM}

The CIBRMM is a DAWNs-based mobility model proposed by Wang et al. [21] which consists of two stages of procedures known as Opening Lifeline Stage (OLS) and Spreading Rescue Stage (SRS).

The CIBRMM is a model in which nodes have to fulfil all tasks in one raw squares area before moving to the next so the Catas trophic Intensity (CI) value should be zero in one of the four adjacent areas. The next movement of nodes can only move in three other directions and cannot move to the area in which CI value equals to zero. The nodes cannot move outside the current area boundary before all areas with the same seismic intensity cleared.

4.1.5.3DA mobility model

The DA mobility model proposed by Aschenbruck et al. [1] is based on the tactical is sues of civil protection where the concept of room separation is introduced. It is believed that the DA model nearly fulfil the requirements for modelling, model with respect to the disaster area scenario. Each node will be assigned to one of the tactical areas (as can be seen in Figure 5). The tactical areas are divided into four different areas which are Incident Location (IL), Casualty Treatment Areas (CTA), Transport Zone (TZ) and Technical Operational Command (TOC). The CTA is then divided into two sub-areas which are Patient Waiting for Treatment (PWT) and Casualties Clearing Station (CCS). Except for the nodes that may need to join/leave their current location, such as transport nodes, all the nodes will be placed in their assigned area.

\subsubsection{LSDMM}

LSDMM [18] is proposed as a solution towards the concerns on the unrealistic representation of complex real-world geographical constraints and the absence of a technique for path modelling in the unknown route. The model makes it possible to place obstacles easily and realistically in large-scale disaster scenarios. As for the simulation area, it is divided into different obstacle regions. The obstacle regions are classified based on their density, which are dense, sparse and obstacle free regions.

Besides, the activity cells are used to model the disaster region. State transitions are used to model the movement of nodes within each cell of the simulation area. In terms of node movement, destination and path selection are determined using a probabilistic approach based on criteria. This approach enables the node to choose the combination of the nearest cell and the cell with the highest node density with a high probability. This model takes not only geographic constraints into account, but also spatial and temporal 
dependencies. Degree of spatialdependence is around 1 for LSDMM, which is higher than RWPA and DA models, whose values are negligible.

4.1.5.5TNMM

The TNMM model [9] is a generalization of the DA model and is inspired by several other mobility models, especially the group-based mobility. The TNMM is goal-oriented and compatible with a range of mobile units as well as stationary wireless sensors. Depending on the created objectives, the nodes can form temporary groups and move in formations throughout the area, simulating the behaviour of realworld tactical units.

\subsubsection{MCMM}

The MCMM [10] combines hierarchical node structure, node operation modes, event-based destination selection, and the presence of physical obstacles that affect the node movement and signal propagation. In general, each node in the MCMM advances at a random speed between zero and a maximum value toward the chosen destination point. When the node reaches this stage, it waits a specified amount of time before repeating the operation. The destination selection process is analogous to that of assigning a task to a node in response to an occurrence that occurred at that site. The MCMM is the first systematic work on mobility models for missioncritical ad hoc networks. As a result, it can be used to generate accurate simulation results about the activity of such networks, especially those involving emergency teams and medical teams.

4.1.5.7RTTMM

The RTTMM is a synthetic mobility model proposed in [22]. The RTTMM resembles the movement of the rescue entities and the unique role assigned to each of them. The RTTMM incorporates five different roles of rescue entities which are relief worker, policeman, ambulance, emergency vehicle, hospital and relief camp and they are categorized into specific tiers. The mobile devices occupied by a policeman and relief worker are regarded as a tier-1 devices. The device mounted by the ambulance and the emergency vehicle are regarded as a tier- 2 devices. The hospital and the relief camp usually placed in a fixed and distant location to avoid recurrence of the events known as Throw Boxes (TBs) and are referred as tier-3 devices.

Only one fixed TBs is allowed at each of the event area and it is placed in the centre. Under RTTMM, the rescue entities are assigned to the designated area based on the intensity of the events so that the relief workers will restrict their movement within the affected radius. Each of the rescue entities will act accordingly in the assigned role making the mobility model seem realistic to the movement of the rescue entities in the real-life situation.

\subsection{Tactical areas and its requirements 4.2.1Tactical areas}

Aschenbruck et al. [1] discussed the characteristics of modelling mobility nodes in the dis aster area scenario. They explained that the node movement of the rescue teams during disaster area was based on the analys is of tactical is sues of civil protection. Situations such as those in crisis areas demonstrate the coordinated movement that is based on the room separation. Typically, the disaster area is divided into four tactical zones: the IL, the CTA (which includes PWT and casualty clearing stations CCS), the TZ, and the TOC.

After the disaster, there will be a few parties involved in each of the tactical areas. The IL is the area where the disaster struck happened. There will be the victims, the rescue teams, including firefighters, police and volunteers and also the trans port nodes, which refer to the ambulance, helicopter or any transportation used during the SAR operation. The victims will then be transferred safely to the second area which is the casualty treatment areas.

At the casualty treatment areas, the involved parties will be the patients, which refer to the victims, medical teams and also the volunteers. The casualty treatment areas consist of two sub-areas which are PWT and CCS. Firstly, the transferred victims will have to wait for the treatment at the PWT. Then, they will be treated accordingly by the medical teams at the CCS.

As for the TZ, the parties involved will be the transport nodes. The transport nodes are referred to the transportation used during the SAR operations such as ambulances, helicopters and others. The node movement of the transport nodes is not limited to one area only. Instead, they will have to go back and forth from the incident location to the casualty treatment areas as they have to transfer the victims.

All the instructions for the SAR operations will be given by one or a few team leaders. They will be the one who will lead their team members during the SAR operations, making and deciding a good strategy to cope with the problem and come out with a solution. They will be in the TOC zone to observe and giving the instructions to their team members. The tactical areas and the involved parties in each of the areas are summarised in Figure 5. 


\subsubsection{Requirements for the tactical areas}

Aschenbruck et al. [5] explained a few requirements that are needed to be considered in the tactical scenario. The tactical communication system is used by military and civil authorities, such as civil defence forces. These forces are highly organised and disciplined, and their activities are highly organised as well. Table 2 shows the relationship between dependencies, mobility models and supported requirements of the tactical areas.

Units and troops often travel in tactical formation within tactical networks. Even if the particular position has a negligible impact, this fact implies group mobility or movement. There will be a leader or group of leaders who will instruct their unit members' movement, including where and how to travel or which area to function in. Generally, the movements are motivated by the tactical considerations. As a result, the units usually take the shortest route to their destination.

The destination is determined by the working location, which is determined by tactical considerations. Typically, both the techniques and the scene are arranged hierarchically. Generally, the site is divided into tactical zones. Each unit or member falls under one of these categories. Usually, groups or members as signed to a particular position would remain close to it. However, some of them, such as the transport nodes, may have special tasks that require them to travel from one place to another. It is very normal for units to leave the scenario and be replaced by others later on, especially in tactical communication sys tems. There can be deaths in the military scenarios, and units transporting patients to hospitals may exist in civil protection scenarios. When units depart from a situation, others are usually requisitioned.

There are several distinct types of units, each with its own unique set of equipment. Some of them own and operate cars, which enables them to travel more quickly. Others are pedestrians, who travel at a slower pace than car owners. As a result, the velocity is heterogeneous depending on the form of nodes.

Finally, since the tactical scenarios take place in areas of destruction, obstacles may arise. Smaller ones can be overlooked because they have a negligible effect on the movement. However, larger ones, such as walls, homes, and so forth, would undoubtedly have a significant effect on them, influencing their movement.

Table 2 Relationship between mobility models and supported the requirements of tactical areas

\begin{tabular}{|c|c|c|c|c|c|c|c|}
\hline Dependency & $\begin{array}{l}\text { Mobility } \\
\text { model }\end{array}$ & $\begin{array}{l}\text { Group } \\
\text { movement }\end{array}$ & $\begin{array}{l}\text { Optimal } \\
\text { paths }\end{array}$ & $\begin{array}{l}\text { Tactical } \\
\text { areas }\end{array}$ & $\begin{array}{l}\text { Nodes } \\
\text { join/leave }\end{array}$ & $\begin{array}{l}\text { Heterogeneous } \\
\text { velocity }\end{array}$ & Obstacles \\
\hline \multirow[t]{4}{*}{ Random } & RW & $\mathrm{X}$ & $\mathrm{X}$ & $(+)$ & $\mathrm{X}$ & $(+)$ & $X$ \\
\hline & RWP & $\mathrm{X}$ & $\mathrm{Y}$ & $(+)$ & $\mathrm{X}$ & $(+)$ & $\mathrm{X}$ \\
\hline & RWPA & $\mathrm{X}$ & $\mathrm{Y}$ & $(+)$ & $\mathrm{X}$ & $(+)$ & $\mathrm{X}$ \\
\hline & Levy-Walk & $\mathrm{X}$ & $\mathrm{X}$ & $\mathrm{X}$ & $\mathrm{X}$ & $\mathrm{X}$ & $\mathrm{X}$ \\
\hline Temporal & GM & $\mathrm{X}$ & $\mathrm{X}$ & $(+)$ & $\mathrm{X}$ & $(+)$ & $\mathrm{X}$ \\
\hline \multirow[t]{3}{*}{ Spatial } & RPGM & $\mathrm{Y}$ & $(+)$ & $(+)$ & $(+)$ & $(+)$ & $(+)$ \\
\hline & HCMM & $\bar{Y}$ & $\mathrm{X}$ & $\mathrm{X}$ & $\mathrm{X}$ & $\mathrm{X}$ & $\mathrm{X}$ \\
\hline & HDBA & $\mathrm{Y}$ & $\mathrm{X}$ & $\mathrm{X}$ & $\mathrm{X}$ & $(+)$ & $\mathrm{Y}$ \\
\hline \multirow[t]{7}{*}{ Geographical } & CoM & $\mathrm{Y}$ & $\mathrm{X}$ & $\mathrm{X}$ & $\mathrm{X}$ & $\mathrm{X}$ & $\mathrm{Y}$ \\
\hline & ND & $\mathrm{Y}$ & $\mathrm{X}$ & $X$ & $\mathrm{X}$ & $\mathrm{X}$ & $\mathrm{X}$ \\
\hline & $\begin{array}{l}\text { Manhattan- } \\
\text { grid }\end{array}$ & $\mathrm{X}$ & $\mathrm{X}$ & $\mathrm{Y}$ & $\mathrm{X}$ & $(+)$ & $\mathrm{X}$ \\
\hline & $\begin{array}{l}\text { Map-based } \\
\text { RWP }\end{array}$ & $\mathrm{X}$ & $\mathrm{X}$ & $\mathrm{X}$ & $\bar{X}$ & $\mathrm{X}$ & $\mathrm{X}$ \\
\hline & ERM & $\mathrm{X}$ & $\mathrm{X}$ & $\mathrm{Y}$ & $\mathrm{X}$ & $\mathrm{Y}$ & $\mathrm{Y}$ \\
\hline & CIBRMM & $\mathrm{Y}$ & $\mathrm{X}$ & $\mathrm{X}$ & $\mathrm{Y}$ & $\mathrm{X}$ & $\mathrm{X}$ \\
\hline & DA & $\mathrm{Y}$ & $\mathrm{Y}$ & $\mathrm{Y}$ & $\mathrm{Y}$ & $\mathrm{Y}$ & $\mathrm{Y}$ \\
\hline \multirow[t]{4}{*}{ Hybrid } & LSDMM & $\mathrm{Y}$ & $\mathrm{Y}$ & $\mathrm{Y}$ & $\mathrm{Y}$ & $\mathrm{Y}$ & $\mathrm{Y}$ \\
\hline & TNMM & $\mathrm{Y}$ & $\mathrm{Y}$ & $\mathrm{Y}$ & $\mathrm{Y}$ & $\mathrm{Y}$ & $\mathrm{Y}$ \\
\hline & MCMM & $\mathrm{Y}$ & $\mathrm{Y}$ & $\mathrm{Y}$ & $\mathrm{Y}$ & $\mathrm{Y}$ & $\mathrm{Y}$ \\
\hline & RTTMM & $\mathrm{Y}$ & $\mathrm{X}$ & $\mathrm{Y}$ & $\mathrm{Y}$ & $\mathrm{Y}$ & $\mathrm{Y}$ \\
\hline
\end{tabular}




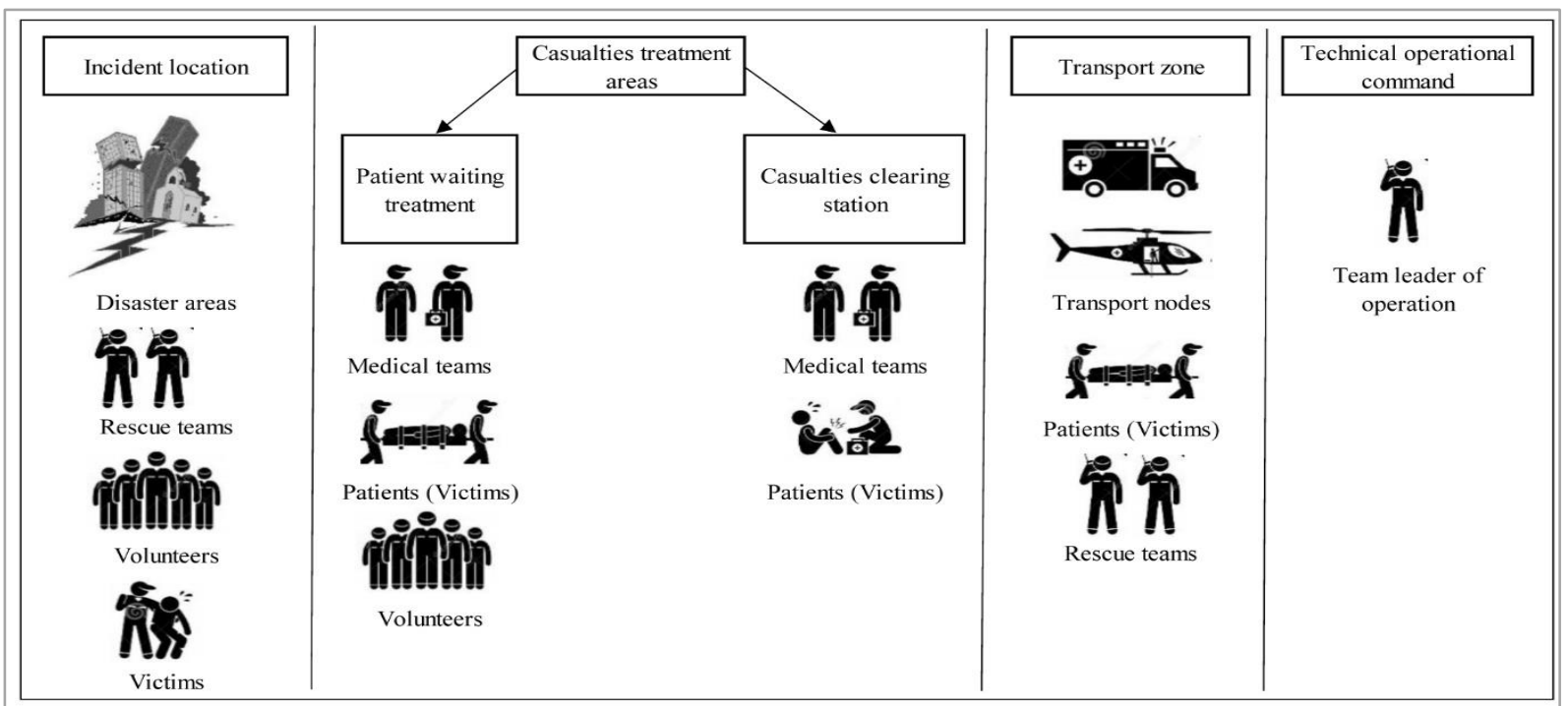

Figure 5 Tactical areas based on separation of rooms

\section{Network simulation tools for MANET}

In a MANET, node mobility is critical. Many of the researchers use simulation as a high-based and lowresources because of the inability to control variables or settings, which limits the number of experiments they can perform. The network simulation tools are essential for trying out ideas on your network before implementing them in your environments.

\subsection{Network simulator 2 (NS-2)}

NS-2 [46], is a discrete-based event simulator and utilises C++ language and Object-Oriented Tool Command Language (Tcl) script. $\mathrm{C}++$ is efficient when using a design, but difficult to visualise. NS-2 is well prepared with protocols, models, algorithms, and useful tools. The overall use of NS-2 is heavily concentrated among researchers due to its ability to generate node and traffic patterns. Besides, NS-2 lets you simulate the wired and wireless network functions. It is an alternative to other simulators to provide a variety of mobility models.

Nonetheless, it has several disadvantages. The design suffers for its lack of modularity and complexity. Some known disadvantages are that it has a high resource usage and is not scalable. NS-2 is typically used for simulations of a few hundred nodes or less.

\subsection{Network simulator 3 (NS-3)}

NS-3 [47] is a free source software which based on discrete events, and utilises C++ language. NS-3 is not the current version of NS-2 and only limited to academic and research purpose. NS3 supports both network-related and non-network-specific research.
Memory management, computation time, and scalability are better in NS-3 than in NS-2. While on the other hand, NS-3 also has a few drawbacks. The models available in NS-3 are quite few, lacks of Graphical User Interface (GUI) to build topology and has limited visualization support.

\subsection{Global mobile information system simulator (GloMoSim)}

GloMoSim [48] is a discrete-based event simulator which utilises a message-based approach. It includes robust models and support networks of thousands of nodes on a large scale. Initially, it supported both wired and wireless networks, but now only wireless networks are supported. However, GloMoSim has not been updated since the year 2000. Thus, no in-depth documentation available for the users.

\subsection{QualNet network simulator}

QualNet [49] is the commercial version simulator based on GloMoSim core and has many features over GloMoSim. It supports high scalability and primarily used to link large heterogeneous networks together. Many models and protocols are available in QualNet for both wired and wireless networks. It is well documented and backed up technically.

QualNet also comes with a powerful and useful GUI support for code development, besides coming with good debugging support and fast simulation results. Moreover, it supports unmatched platform portability and interface flexibility. However, it is a bit pricey, some source codes of files may be hidden, slow installation, and hard to deal with in Linux. 


\subsection{Objective modular NETwork testbed in C++ (OMNet++)}

OMNET++ [50] is an object-oriented discrete event network simulator. OMNET++ is free for academic purpose, while the commercial version of OMNET++ namely OMNEST can be obtained from Simulcraft Incorporation for its license. OMNET++ has a generic architecture. OMNeT++ provides a large library class for developing various modules. Besides, it is able to handle both event-driven and process-based programming. Thus, it would be perfectly applicable to MANET simulation. However, OMNET++ has limited protocol supports, and their performance analysis as well as documentation seems to be inadequate [48].

\subsection{Optimized network engineering Tool (OPNet)} OPNet [48] is a well-established and most widely used commercial simulation environment, written in the $\mathrm{C}++$ language in which it simulates the behaviour and the performance of any type of the network. Compared to other simulators, OPNet has more advantages in terms of power and versatility. OPNet capable of executing and monitoring several scenarios in a concurrent manner. Furthermore, it provides a clear, user-friendly visualisation and grid computing for distributed simulation. Despite its lacking of energy model, OPNET is a bit pricey for the commercial purpose. It only provides limited wireless mobility and supports a limited set of protocols.

\subsection{0pportunistic networking environment (ONE)} ONE [51] is a discrete-based event simulator, programmed in Java language with the purpose of examining DTN routing and application protocols. It is capable of generating node movement using a variety of movement models, either synthetic or existing. It also routes messages among nodes using a variety of DTN routing algorithms and node types. ONE simulator allowed the users to display both mobility and message transmission in real time via GUI. Besides, it allows the user to import mobility data from real-world traces or from other mobility generators. Numerous reports, ranging from the node movement to message passing and general statistics, can be provided. However, it can be unfamiliar to the user to deal with as the provided documentation seems inadequate.

\subsection{Network simulator (NetSim)}

NetSim [52] is a discrete-based event simulator and open source software, which is suitable for the network Research and Development (R\&D) purpose. NetSim covers different type of networks such as Wi-
Max, WLAN, Wireless Sensor Networks (WSNs), MANETs and others. It can modify and use the protocol libraries easily due to their simplicity. NetSim allows the custom code to be debugged during the simulation. Thus, minimizes the time needed to build and run the simulation to meet the user specific requirements. Besides, it has excellent programmability and inbuilt analysis framework and packet-animator. However, NetSim is restricted to the academic purpose.

5.9Java in simulation time (JiST) / scalable wireless network simulator (SWANS)

JiST/SWANS [53] represents SWANS built on JiST platform. It is a Java-based discrete simulator and can be simulated in a large network. By using JiST/SW ANS, the computational overhead is low and requires less memory. However, the last version was updated in 2005 and no new development after that.

\subsection{Java-based simulator (JSim)}

JSim [54] is a Java-based discrete event simulator that is extensible and reusable across platforms. It creates and analyses quantitative numeric models based on experimental reference data. The calculations of JSim model are described in JSim's Mathematical Modelling Language (MML). It is a simple-to-read text-based language, and MML models are frequently expressed mathematically. It offers flexibility and the GUI library is also provided. The weakness of JSim is it required longer execution time.

\section{Discussion}

\subsection{Simulation parameters}

To measure the network efficiency of the mobility model, simulation parameters based on the specific scenario are considered. The mobility model is used to describe the movement of mobile users over time by taking into account their position, velocity, and direction. The radio propagation model is a mathematical experiment that is used to characterise radio wave propagation as a work of recurrence, distinct, and other conditions.

Bandwidth refers to the maximum amount of data that can be transferred over a particular link in a given amount of time, but does not indicate the speed at which data bits travel from one place to another. A packet is a small amount of data sent over a network such as a Local Area Network (LAN) or the Internet. Sending smaller packet size makes a difference guarantee each area is trans mitted successfully instead of sending a large file as a single block of data. In a case such as disaster area scenario, it is crucial to 
determine the right packet size, as we want to ensure the packet containing the message is successfully sent and delivered.

Traffic model portrays the way the process of how a number of packets arrived to nodes on the network. Constant Bit Rate (CBR) is one of the most commonly used traffic patterns in the networks. Number of nodes refer to the number of mobile nodes in the designated scenario. Speed shows how fast the movement of nodes involved. Normally, the speed of pedestrian is around $1 \mathrm{~m} / \mathrm{s}$ to $5 \mathrm{~m} / \mathrm{s}$. While, the speed of vehicles is around $5 \mathrm{~m} / \mathrm{s}$ to $12 \mathrm{~m} / \mathrm{s}$. Simulation area portrays the size of the designated area for such scenario. Simulation time refers to the execution time of the simulation to run. Area coverage is the total amount of covered area during execution time.
A comparison of the existing mobility models used in terms of simulation parameters is presented for future references. The comparison made is based on the details given by the authors in their existing papers. Some details might be missing as the authors do not stated about it. Table 3 and Table 4 shows the simulation parameters used by the authors in their related papers.

6.2Comparative analysis on related works

This paper presents a comparative study of the related work with respect to the approaches, mobility, model, scenario or environment, performance metrics and limitations. The comparative analysis is shown in Table 5. Complete list of abbreviations is shown in Appendix $I$.

Table 3 Simulation parameters I

\begin{tabular}{|c|c|c|c|c|c|c|}
\hline Author & $\begin{array}{l}\text { Mobility } \\
\text { Model }\end{array}$ & $\begin{array}{l}\text { Propagation } \\
\text { Model }\end{array}$ & Number of nodes & Speed $(\mathrm{m} / \mathrm{s})$ & $\begin{array}{l}\text { Simulation } \\
\text { area }(\mathbf{m} \times \mathbf{m})\end{array}$ & $\begin{array}{l}\text { Coverage } \\
\text { (m) }\end{array}$ \\
\hline $\begin{array}{ll}\text { Conceicao } & \text { and } \\
\text { Curado [14] } & \end{array}$ & $\begin{array}{l}\text { HDBA, } \\
\text { RWP }\end{array}$ & N/A & $25,50,75,100$ & $1-5$ & $500 \times 500$ & 150 \\
\hline Boldrini et al. [7] & $\begin{array}{l}\text { HCMM, } \\
\text { CMM [7] }\end{array}$ & N/A & 30 & 5 & $10 \times 10$ & N/A \\
\hline Wang et al. [21] & $\begin{array}{l}\text { CIBRMM, } \\
\text { TMM }\end{array}$ & N/A & 100 & N/A & $20 \times 20$ & N/A \\
\hline $\begin{array}{l}\text { Rollo and } \\
\text { Komenda [9] }\end{array}$ & $\begin{array}{l}\text { TNMM, } \\
\text { RWP }\end{array}$ & N/A & $\begin{array}{l}\text { Robots (5) } \\
\text { Humans (5) }\end{array}$ & N/A & N/A & 100 \\
\hline $\begin{array}{l}\text { Aschenbruck et al. } \\
\text { [1] }\end{array}$ & $\begin{array}{l}\text { DA, GM, } \\
\text { RWP }\end{array}$ & N/A & 150,200 & $1-2$ & $\begin{array}{l}200 \times 200 \\
550 \times 500\end{array}$ & $50-100$ \\
\hline $\begin{array}{l}\text { Martini-Campillo } \\
\text { et al. [15] }\end{array}$ & DA & N/A & $10,30,50,70$ & N/A & $\begin{array}{l}700 \times 600 \\
50 \times 50\end{array}$ & 60 \\
\hline Ebenezer [18] & $\begin{array}{l}\text { LSDMM, } \\
\text { RWPA, } \\
\text { DA }\end{array}$ & N/A & 1500 & N/A & N/A & 200 \\
\hline $\begin{array}{l}\text { Papageorgiou et } \\
\text { al. [10] }\end{array}$ & $\begin{array}{l}\text { MCMM, } \\
\text { HUMO, } \\
\text { OM, RWP }\end{array}$ & $\begin{array}{l}\text { Two-Ray } \\
\text { Ground }\end{array}$ & 50 & $1,2,5,7$ & N/A & N/A \\
\hline Stute et al. [23] & $\begin{array}{l}\text { ND, RWP, } \\
\text { MAP- } \\
\text { based RWP }\end{array}$ & N/A & 500 & $0.5-1.5$ & $5000 \times 7000$ & 10 \\
\hline Reina et al. [16] & DA & $\begin{array}{l}\text { Two-Ray } \\
\text { Ground }\end{array}$ & 102 & $\begin{array}{l}\text { Pedestrians (1-2) } \\
\text { Vehicles }(5-12)\end{array}$ & $850 \times 300$ & 150 \\
\hline Reina et al. [19] & DA & $\begin{array}{l}\text { Two-Ray } \\
\text { Ground, } \\
\text { Shadowing }\end{array}$ & 200 & $\begin{array}{l}\text { Pedestrians (1-2) } \\
\text { Vehicles }(5-12)\end{array}$ & $550 \times 500$ & 30 \\
\hline Reina et al. [12] & $\overline{D A}$ & $\begin{array}{l}\text { Two-Ray } \\
\text { Ground }\end{array}$ & 150,200 & $\begin{array}{l}\text { Pedestrians (1-2) } \\
\text { Vehicles }(5-12)\end{array}$ & $\begin{array}{l}350 \times 200 \\
200 \times 200 \\
550 \times 500\end{array}$ & 30 \\
\hline Nelson et al. [8] & ERM, RW & N/A & $\begin{array}{l}\text { Civilians (75) } \\
\text { Ambulance (10) } \\
\text { Police (15) }\end{array}$ & $\begin{array}{l}\text { Civilians (1-4) } \\
\text { Ambulance (17- } \\
20) \\
\text { Police }(17-20)\end{array}$ & $1000 \times 1000$ & 150 \\
\hline
\end{tabular}


Nor Aida Mahiddin et al.

\begin{tabular}{|c|c|c|c|c|c|c|}
\hline Author & $\begin{array}{l}\text { Mobility } \\
\text { Model }\end{array}$ & $\begin{array}{l}\text { Propagation } \\
\text { Model }\end{array}$ & Number of nodes & Speed $(\mathrm{m} / \mathrm{s})$ & $\begin{array}{l}\text { Simulation } \\
\text { area }(\mathbf{m} \times \mathbf{m})\end{array}$ & $\begin{array}{l}\text { Coverage } \\
\text { (m) }\end{array}$ \\
\hline $\begin{array}{l}\text { Pomportes et al. } \\
\text { [11] }\end{array}$ & $\begin{array}{l}\text { CoM, } \\
\text { RPGM, } \\
\text { Levy-walk, } \\
\text { RWP }\end{array}$ & N/A & $\begin{array}{l}\text { RWP \& Levy- } \\
\text { walk: } 400 \\
\text { CoM, RPGM, } \\
\text { RWP, Levy-walk: } \\
1000 \\
\text { Obstacles: } 10 \\
\text { No obstacles: } 1200\end{array}$ & N/A & $\begin{array}{l}\text { RWP \& Levy- } \\
\text { walk: } \\
800 \text { x } 800 \\
\text { Obstacles: } \\
600 \text { x } 600 \\
\text { No obstacles: } \\
1200 \text { x } 1200\end{array}$ & N/A \\
\hline Reina et al. [17] & DA & $\begin{array}{l}\text { Two-Ray } \\
\text { Ground }\end{array}$ & $\begin{array}{l}\text { IL: } 30 \\
\text { PWT: } 10 \\
\text { CCS: } 15 \\
\text { TZ: } 30 \\
\text { TOC: } 2\end{array}$ & $\begin{array}{l}\text { Pedestrians (1-2) } \\
\text { Vehicles }(5-12)\end{array}$ & $\begin{array}{l}\text { IL: } 200 \times 200 \\
\text { PWT: } 100 \quad \text { x } \\
100 \\
\text { CCS: } 150 \times 150 \\
\text { TZ: } 250 \times 200 \\
\text { TOC: } 100 \times 50\end{array}$ & 50 \\
\hline $\begin{array}{l}\text { Raffelsberger and } \\
\text { Hellwagner [13] }\end{array}$ & $\overline{\mathrm{DA}}$ & $\begin{array}{l}\text { Wireless } \\
\text { Shadowing } \\
\text { model }\end{array}$ & 25 & N/A & $400 \times 300$ & 100 \\
\hline Kim et al. [27] & RWP & N/A & $10,15,20,25,30$ & $1-5$ & $80 \times 80$ & 22 \\
\hline $\begin{array}{l}\text { Younes and } \\
\text { Albalawi [28] }\end{array}$ & RWP & N/A & $20-120$ & $1-20$ & $500 \times 300$ & $100-300$ \\
\hline Kim et al. [26] & RPGM & N/A & $25,50,75$ & N/A & $1200 \times 1200$ & N/A \\
\hline Sani et al. [24] & DA & $\begin{array}{l}\text { Two-Ray } \\
\text { Ground }\end{array}$ & $65,95,125,155$ & N/A & $800 \times 800$ & N/A \\
\hline $\begin{array}{l}\text { Al-Shehri et al. } \\
{[25]}\end{array}$ & $\begin{array}{l}\text { RPGM, } \\
\text { RWP, } \\
\text { Manhattan }\end{array}$ & $\begin{array}{l}\text { Two-Ray } \\
\text { Ground, Free } \\
\text { space model }\end{array}$ & $25-250$ & N/A & $1000 \times 1000$ & N/A \\
\hline $\begin{array}{l}\text { Gondaliya and } \\
\text { Atiquzzaman [22] }\end{array}$ & $\begin{array}{l}\text { RTTMM, } \\
\text { ERM }\end{array}$ & N/A & 52 & $\begin{array}{l}\text { Relief workers (3) } \\
\text { Ambulance and } \\
\text { emergency } \\
\text { vehicle (12) } \\
\text { Police (7) }\end{array}$ & $3000 \times 3000$ & 50 \\
\hline Arbia et al. [20] & $\mathrm{DA}$ & N/A & $\begin{array}{l}\text { Rescuer (100) } \\
\text { Firefighters (78) } \\
\text { Ambulance (30) }\end{array}$ & N/A & $480 \times 260$ & N/A \\
\hline
\end{tabular}

Table 4 Simulation parameters II

\begin{tabular}{|c|c|c|c|c|c|}
\hline Author & Mobility Model & $\begin{array}{l}\text { B/width } \\
\text { (Mbps) }\end{array}$ & Packet size (kB) & Traffic pattern & $\begin{array}{l}\text { Simulation } \\
\text { time }\end{array}$ \\
\hline Conceicao and Curado [14] & HDBA, RWP & 54 & 0.5 & N/A & $900 \mathrm{~s}$ \\
\hline Boldrini et al. [7] & HCMM, CMM & N/A & N/A & N/A & N/A \\
\hline Wang et al. [21] & CIBRMM, TMM & N/A & N/A & N/A & N/A \\
\hline Rollo and Komenda [9] & TNMM, RWP & N/A & N/A & N/A & N/A \\
\hline Aschenbruck et al. [1] & DA, GM, RWP & 0.008 & N/A & $\mathrm{N} / \mathrm{A}$ & $5 \mathrm{~min}$ \\
\hline Martini-Campillo et al. [15] & $\overline{\mathrm{DA}}$ & 54 & 128 & N/A & $6000 \mathrm{~s}$ \\
\hline Ebenezer [18] & $\begin{array}{l}\text { LSDMM, RWPA, } \\
\text { DA }\end{array}$ & N/A & N/A & N/A & $10000 \mathrm{~s}$ \\
\hline Papageorgiou et al. [10] & $\begin{array}{ll}\text { MCMM, HUMO, } \\
\text { OM, RWP }\end{array}$ & N/A & 0.062 & CBR & N/A \\
\hline Stute et al. [23] & $\begin{array}{l}\text { ND, RWP, MAP- } \\
\text { based RWP }\end{array}$ & 2 & $50-100$ & N/A & 7 days \\
\hline Reina et al. [16] & DA & N/A & N/A & CBR & $150 \mathrm{~s}$ \\
\hline Reina et al. [19] & $\mathrm{DA}$ & 2 & 0.5 & CBR & $300 \mathrm{~s}$ \\
\hline Reina et al. [12] & DA & 2 & 0.5 & CBR & $1500 \mathrm{~s}$ \\
\hline Nelson et al. [8] & ERM, RW & N/A & N/A & N/A & $1500 \mathrm{~s}$ \\
\hline
\end{tabular}




\begin{tabular}{|c|c|c|c|c|c|}
\hline Author & Mobility Model & $\begin{array}{l}\text { B/width } \\
\text { (Mbps) }\end{array}$ & Packet size (kB) & Traffic pattern & $\begin{array}{l}\text { Simulation } \\
\text { time }\end{array}$ \\
\hline Pomportes et al. [11] & $\begin{array}{l}\text { CoM, RPGM, Levy- } \\
\text { walk, RWP }\end{array}$ & N/A & N/A & N/A & N/A \\
\hline Reina et al. [17] & DA & 2 & 0.5 & CBR & $300 \mathrm{~s}$ \\
\hline $\begin{array}{l}\text { Raffelsberger and Hellwagner } \\
\text { [13] }\end{array}$ & $\overline{\mathrm{DA}}$ & 54 & N/A & UDP & $3000 \mathrm{~s}$ \\
\hline Kim et al. [27] & RWP & N/A & 1 & N/A & $600 \mathrm{~s}$ \\
\hline Younes and Albalawi [28] & RWP & 8 & 0.5 & CBR & $1100 \mathrm{~s}$ \\
\hline Kim et al. [26] & RPGM & N/A & N/A & CBR & N/A \\
\hline Sani et al. [24] & DA & N/A & 0.5 & FTP & N/A \\
\hline Al-Shehri et al. [25] & $\begin{array}{l}\text { RPGM, RWP, } \\
\text { Manhattan }\end{array}$ & N/A & 0.5 & N/A & N/A \\
\hline $\begin{array}{l}\text { Gondaliya and Atiquzzaman } \\
\text { [22] }\end{array}$ & RTTMM, ERM & 2 & 25 & N/A & $6000 \mathrm{~s}$ \\
\hline Arbia et al. $[20]$ & DA & 54 & N/A & N/A & $3600 \mathrm{~s}$ \\
\hline
\end{tabular}

Table 5 Comparative analysis of the related works

\begin{tabular}{|c|c|c|c|c|c|}
\hline Author & Approach & $\begin{array}{l}\text { Mobility } \\
\text { model }\end{array}$ & $\begin{array}{l}\text { Scenario/ } \\
\text { Environment }\end{array}$ & $\begin{array}{l}\text { Performance } \\
\text { metrics }\end{array}$ & Limitations \\
\hline $\begin{array}{l}\text { Aschenbruck } \\
\text { et al. [1] }\end{array}$ & $\begin{array}{l}\text { Comparison analysis in } \\
\text { terms of performance } \\
\text { between the selected } \\
\text { mobility models by } \\
\text { varying the } \\
\text { transmission range. }\end{array}$ & $\begin{array}{l}\text { DA, GM, } \\
\text { RWP }\end{array}$ & $\begin{array}{lr}\text { MANET } & \text { in } \\
\text { disaster } & \text { area } \\
\text { scenario. } & \end{array}$ & $\begin{array}{l}\text { Relative mobility } \\
\text { rate. } \\
\text { Average } \\
\text { degree. } \\
\text { Average } \\
\text { duration. } \\
\text { Minimum number } \\
\text { of links between a } \\
\text { node and its } \\
\text { neighbour. } \\
\text { PDF. } \\
\text { NRL. } \\
\text { Transmission } \\
\text { delay. }\end{array}$ & $\begin{array}{l}\text { Energy consumption } \\
\text { and overhead were not } \\
\text { considered. } \\
\text { Additional aspect like } \\
\text { complex radio } \\
\text { propagation model, } \\
\text { including obstacles } \\
\text { should be considered } \\
\text { in the future. }\end{array}$ \\
\hline $\begin{array}{l}\text { Boldrini et al. } \\
\text { [7] }\end{array}$ & $\begin{array}{l}\text { Incorporating the } \\
\text { concepts of CMM } \\
\text { model and determining } \\
\text { preferential locations. }\end{array}$ & $\begin{array}{l}\text { HCMM, } \\
\text { CMM }\end{array}$ & $\begin{array}{l}\text { Opportunistic } \\
\text { network. }\end{array}$ & $\begin{array}{l}\text { Contact duration. } \\
\text { Intercontact time. }\end{array}$ & $\begin{array}{l}\text { Evaluation on network } \\
\text { performance metrics } \\
\text { were not considered. }\end{array}$ \\
\hline $\begin{array}{l}\text { Nelson et al. } \\
{[8]}\end{array}$ & $\begin{array}{l}\text { Implementation of } \\
\text { concept "Flee" and } \\
\text { "Approach" actions. }\end{array}$ & ERM, RW & $\begin{array}{l}\text { Disaster } \quad \text { area } \\
\text { scenario. }\end{array}$ & $\begin{array}{l}\text { Changes in network } \\
\text { topology } \\
\text { (topological } \\
\text { implications for the } \\
\text { network graph). }\end{array}$ & $\begin{array}{l}\text { Communication } \\
\text { between the nodes was } \\
\text { not considered. }\end{array}$ \\
\hline $\begin{array}{l}\text { Rollo and } \\
\text { Komenda [9] }\end{array}$ & $\begin{array}{l}\text { Synthetic mobility } \\
\text { model based on task- } \\
\text { oriented methodology. }\end{array}$ & $\begin{array}{l}\text { TNMM, } \\
\text { RWP }\end{array}$ & Tactical network. & $\begin{array}{lr}\text { Node } & \text { spatial } \\
\text { distribution. } & \\
\text { Average } & \text { node } \\
\text { degree. } & \\
\end{array}$ & $\begin{array}{l}\text { No comprehensive } \\
\text { study on the efficiency } \\
\text { in terms of node } \\
\text { mobility. }\end{array}$ \\
\hline $\begin{array}{l}\text { Papageorgiou } \\
\text { et al. [10] }\end{array}$ & $\begin{array}{l}\text { Systematic work on } \\
\text { mobility models that } \\
\text { combines hierarchical } \\
\text { node, operation modes, } \\
\text { event-based destination } \\
\text { selection and presence } \\
\text { of physical obstacles. }\end{array}$ & $\begin{array}{l}\text { MCMM, } \\
\text { HUMO, } \\
\text { OM, RWP }\end{array}$ & $\begin{array}{l}\text { Mission critical } \\
\text { in MANET. }\end{array}$ & $\begin{array}{l}\text { Network } \\
\text { connectivity and } \\
\text { impact on a } \\
\text { MANET } \\
\text { efficiency. }\end{array}$ & $\begin{array}{l}\text { Energy consumption } \\
\text { and overhead were not } \\
\text { considered. }\end{array}$ \\
\hline
\end{tabular}


Nor Aida Mahiddin et al.

\begin{tabular}{|c|c|c|c|c|c|}
\hline Author & Approach & $\begin{array}{l}\text { Mobility } \\
\text { model }\end{array}$ & $\begin{array}{l}\text { Scenario/ } \\
\text { Environment }\end{array}$ & $\begin{array}{l}\text { Performance } \\
\text { metrics }\end{array}$ & Limitations \\
\hline $\begin{array}{l}\text { Pomportes et } \\
\text { al. [11] }\end{array}$ & $\begin{array}{l}\text { A composite mobility } \\
\text { model that incorporates } \\
\text { a group movement, } \\
\text { mobility, human } \\
\text { mobility and obstacle } \\
\text { avoidance, which were } \\
\text { RPGM, Levy-Walk and } \\
\text { Voronoi diagram } \\
\text { respectively. }\end{array}$ & $\begin{array}{l}\text { CoM, } \\
\text { RPGM, } \\
\text { Levy- } \\
\text { Walk, } \\
\text { RWP }\end{array}$ & $\begin{array}{l}\text { Disaster } \quad \text { area } \\
\text { scenario. }\end{array}$ & $\begin{array}{l}\text { Distribution } \quad \text { of } \\
\text { node degree. } \\
\text { Average } \\
\text { degree. } \\
\begin{array}{l}\text { Contact } \\
\text { intercontact times. }\end{array}\end{array}$ & $\begin{array}{l}\text { Evaluation } \\
\text { focused to the } \\
\text { microscopic scale of } \\
\text { the network. }\end{array}$ \\
\hline $\begin{array}{l}\text { Reina et al. } \\
{[12]}\end{array}$ & $\begin{array}{lr}\text { Evaluate } & \text { performance } \\
\text { of MANET routing } \\
\text { protocols which were } \\
\text { AODV, DSR and } \\
\text { AOMDV under the } \\
\text { disaster } \\
\text { model. mobility }\end{array}$ & DA & $\begin{array}{l}\text { Disaster area } \\
\text { scenario. }\end{array}$ & $\begin{array}{l}\text { Throughput. } \\
\text { PDF. } \\
\text { NRL. } \\
\text { Average E2E. }\end{array}$ & $\begin{array}{l}\text { Communication paths } \\
\text { between nodes have a } \\
\text { limited lifespan. }\end{array}$ \\
\hline Kim et al. [27] & $\begin{array}{l}\text { MANET location- } \\
\text { based routing approach } \\
\text { by applying dual } \\
\text { channels, known as } \\
\text { sub-GHz and } 2.4 \mathrm{GHz} \\
\text { for the indoor disaster } \\
\text { environment. }\end{array}$ & RWP & $\begin{array}{l}\text { Firefighter } \\
\text { communication } \\
\text { indoor disaster } \\
\text { environment. }\end{array}$ & $\begin{array}{l}\text { PDR. } \\
\text { E2E. } \\
\text { Initial routing table } \\
\text { configuration time. }\end{array}$ & $\begin{array}{l}\text { Multicasting and } \\
\text { broadcasting schemes } \\
\text { need to be considered } \\
\text { for performance } \\
\text { evaluation under such } \\
\text { scenario. }\end{array}$ \\
\hline $\begin{array}{l}\text { Raffelsberger } \\
\text { and } \\
\text { Hellwagner } \\
{[13]}\end{array}$ & $\begin{array}{l}\text { Evaluate performance } \\
\text { of MANET routing } \\
\text { protocols which were } \\
\text { AODV, OLSR, DYMO } \\
\text { and BATMAN under } \\
\text { the disaster mobility } \\
\text { model. }\end{array}$ & DA & $\begin{array}{l}\text { Emergency } \\
\text { response } \\
\text { scenario. }\end{array}$ & $\begin{array}{l}\text { PDR. } \\
\text { Average PDR of } \\
\text { mobile nodes } \\
\text { operating inside the } \\
\text { facility. } \\
\text { Cumulative } \\
\text { distribution } \\
\text { function of the hop } \\
\text { count. } \\
\text { Packet delivery } \\
\text { delay. }\end{array}$ & $\begin{array}{ll}\text { Some nodes are } \\
\text { intermittently } \\
\text { connected which } \\
\text { results in higher } \\
\text { packet loss. }\end{array}$ \\
\hline $\begin{array}{l}\text { Conceicao and } \\
\text { Curado [14] }\end{array}$ & $\begin{array}{l}\text { Mobility model based } \\
\text { on force vector. }\end{array}$ & $\begin{array}{l}\text { HDBA, } \\
\text { RWP }\end{array}$ & Search missions. & $\begin{array}{l}\text { Density } \\
\text { distribution of } \\
\text { nodes. } \\
\text { Node degree. } \\
\text { Area coverage. } \\
\text { Topology changes. } \\
\text { Throughput. } \\
\end{array}$ & $\begin{array}{l}\text { Scalability of the } \\
\text { network was not } \\
\text { considered. }\end{array}$ \\
\hline $\begin{array}{l}\text { Martini- } \\
\text { Campillo et al. } \\
{[15]}\end{array}$ & $\begin{array}{l}\text { Evaluates performance } \\
\text { of opportunistic routing } \\
\text { protocols under disaster } \\
\text { mobility. }\end{array}$ & DA & $\begin{array}{l}\text { Emergency } \\
\text { scenario. }\end{array}$ & $\begin{array}{l}\text { Delivery rate. } \\
\text { Lifetime. }\end{array}$ & $\begin{array}{l}\text { Not energy-efficient } \\
\text { towards a dense } \\
\text { network of nodes or } \\
\text { large number of } \\
\text { messages. }\end{array}$ \\
\hline $\begin{array}{l}\text { Reina et al. } \\
{[16]}\end{array}$ & $\begin{array}{l}\text { Evolutionary } \\
\text { computational } \\
\text { approach by applying } \\
\text { adaptive broadcasting } \\
\text { scheme based on } \\
\text { topological conditions. }\end{array}$ & $\overline{D A}$ & $\begin{array}{l}\text { Disaster } \\
\text { scenario. }\end{array}$ & $\begin{array}{l}\text { Reachability. } \\
\text { Saved-Rebroadcast } \\
\text { (SRB). }\end{array}$ & $\begin{array}{lr}\text { Performance } & \\
\text { evaluation } & \text { onl } \\
\text { focused } & \mathrm{o} \\
\text { connectivity } & \\
\text { improvement. } & \end{array}$ \\
\hline
\end{tabular}


International Journal of Advanced Technology and Engineering Exploration, Vol 8(80)

\begin{tabular}{|c|c|c|c|c|c|}
\hline Author & Approach & $\begin{array}{l}\text { Mobility } \\
\text { model }\end{array}$ & $\begin{array}{l}\text { Scenario/ } \\
\text { Environment }\end{array}$ & $\begin{array}{l}\text { Performance } \\
\text { metrics }\end{array}$ & Limitations \\
\hline $\begin{array}{l}\text { Reina et } \text { al. } \\
{[17]}\end{array}$ & $\begin{array}{l}\text { Performance evaluation } \\
\text { of different MANET } \\
\text { routing protocols under } \\
\text { disaster mobility. }\end{array}$ & DA & $\begin{array}{l}\text { Disaster area } \\
\text { scenario. }\end{array}$ & $\begin{array}{l}\text { Dropped packets } \\
\text { and hop count. } \\
\text { Throughput. } \\
\text { PDF. } \\
\text { NRL. } \\
\text { E2E. }\end{array}$ & $\begin{array}{l}\text { Issue of difficult } \\
\text { conditions and limited } \\
\text { connectivity. }\end{array}$ \\
\hline Ebenezer [18] & $\begin{array}{l}\text { Destination and path } \\
\text { selection using a } \\
\text { probabilistic approach } \\
\text { based on criteria. }\end{array}$ & $\begin{array}{l}\text { LSDMM. } \\
\text { RWPA, } \\
\text { DA }\end{array}$ & $\begin{array}{l}\text { Large scale } \\
\text { disaster scenario. }\end{array}$ & $\begin{array}{lr}\text { Average } & \text { node } \\
\text { degree. } & \\
\text { Average } & \text { link } \\
\text { duration. } & \end{array}$ & $\begin{array}{l}\text { Overhead may occur } \\
\text { as the transmission } \\
\text { range } \\
\text { causing decrement in } \\
\text { overall network } \\
\text { capacity. }\end{array}$ \\
\hline $\begin{array}{l}\text { Reina et al. } \\
{[19] \mathrm{A}}\end{array}$ & $\begin{array}{l}\text { New probabilistic } \\
\text { approach based on } \\
\text { similarity/dissimilarity } \\
\text { metrics. }\end{array}$ & DA & $\begin{array}{l}\text { MANET in } \\
\text { disaster response } \\
\text { scenarios. }\end{array}$ & $\begin{array}{l}\text { Reachability. } \\
\text { Retransmissions. } \\
\text { Delay. }\end{array}$ & $\begin{array}{l}\text { Only considered the } \\
\text { performance of certain } \\
\text { routing protocols. }\end{array}$ \\
\hline $\begin{array}{l}\text { Arbia et al. } \\
{[20]}\end{array}$ & $\begin{array}{l}\text { Evaluate performance } \\
\text { of different routing } \\
\text { protocols while using } \\
\text { various communication } \\
\text { technologies. }\end{array}$ & DA & $\begin{array}{l}\text { Fire trigger in the } \\
\text { shopping } \\
\text { mall/urban } \\
\text { critical and } \\
\text { emergency } \\
\text { scenario. }\end{array}$ & $\begin{array}{l}\text { PRR. } \\
\text { Packet delay. } \\
\text { Energy } \\
\text { consumption. }\end{array}$ & $\begin{array}{ll}\text { The study } & \text { only } \\
\text { considered for } & \text { small } \\
\text { tactical teams. } & \end{array}$ \\
\hline $\begin{array}{l}\text { Wang et al. } \\
{[21]}\end{array}$ & $\begin{array}{l}\text { Movement of nodes } \\
\text { based on the } \\
\text { catastrophic intensity } \\
\text { value. }\end{array}$ & $\begin{array}{l}\text { CIBRMM, } \\
\text { TMM }\end{array}$ & $\begin{array}{ll}\text { Disaster Area } \\
\text { Wireless } \\
\text { Networks } \\
\text { (DAWNs). }\end{array}$ & $\begin{array}{l}\text { Rescue time with } \\
\text { different number of } \\
\text { affected areas and } \\
\text { catastrophic } \\
\text { intensity. }\end{array}$ & $\begin{array}{l}\text { Communication } \\
\text { between nodes was } \\
\text { not considered, thus } \\
\text { no evaluation of } \\
\text { network performance. }\end{array}$ \\
\hline $\begin{array}{l}\text { Gondaliya and } \\
\text { Atiquzzaman } \\
\text { [22] }\end{array}$ & $\begin{array}{l}\text { Incorporation of five } \\
\text { different roles of rescue } \\
\text { entities, whereas the } \\
\text { rescue entities is } \\
\text { assigned to the } \\
\text { designated area based } \\
\text { on the intensity of the } \\
\text { events so that the relief } \\
\text { workers will restrict } \\
\text { their movement within } \\
\text { the affected radius. }\end{array}$ & $\begin{array}{l}\text { RTTMM, } \\
\text { ERM }\end{array}$ & $\begin{array}{l}\text { Post-disaster } \\
\text { scenario. }\end{array}$ & $\begin{array}{l}\text { Delivery ratio. } \\
\text { Latency. } \\
\text { Average overhead } \\
\text { ratio. } \\
\text { Cost per message. }\end{array}$ & $\begin{array}{l}\text { Decrement in message } \\
\text { size as a number of } \\
\text { devices and buffer } \\
\text { sizes varied. }\end{array}$ \\
\hline $\begin{array}{l}\text { Stute et al. } \\
{[23]}\end{array}$ & $\begin{array}{lr}\text { Reverse engineering, } \\
\text { human mobility } \\
\text { approach based on } 126 \\
\text { knowledge experts. }\end{array}$ & $\begin{array}{l}\text { ND, RWP, } \\
\text { Map-based } \\
\text { RWP }\end{array}$ & $\begin{array}{l}\text { DTNs in large- } \\
\text { scale natural } \\
\text { disasters. }\end{array}$ & $\begin{array}{l}\text { Delivery rate. } \\
\text { Delay. } \\
\text { Buffer occupancy. } \\
\text { Delivery rate (for } \\
\text { different roles). }\end{array}$ & $\begin{array}{l}\text { Scalability of the } \\
\text { network and realistic } \\
\text { communication } \\
\text { performance were not } \\
\text { considered. }\end{array}$ \\
\hline Sani et al. [24] & $\begin{array}{lr}\text { Evaluate } & \text { TCP } \\
\text { performance } & \text { in } \\
\text { MANET routing } \\
\text { protocols by varying } \\
\text { traffic scenario and } \\
\text { node density. }\end{array}$ & $\overline{D A}$ & $\begin{array}{l}\text { Disaster recovery } \\
\text { scenario. }\end{array}$ & $\begin{array}{l}\text { Average } \\
\text { throughput. } \\
\text { PDR. } \\
\begin{array}{l}\text { Average } \\
\text { delay. }\end{array}\end{array}$ & $\begin{array}{l}\text { Throughput in all } \\
\text { routing protocols } \\
\text { decreases as the TCP } \\
\text { connection increase. }\end{array}$ \\
\hline
\end{tabular}


Nor Aida Mahiddin et al.

\begin{tabular}{|c|c|c|c|c|c|}
\hline Author & Approach & $\begin{array}{l}\text { Mobility } \\
\text { model }\end{array}$ & $\begin{array}{l}\text { Scenario/ } \\
\text { Environment }\end{array}$ & $\begin{array}{l}\text { Performance } \\
\text { metrics }\end{array}$ & Limitations \\
\hline $\begin{array}{l}\text { Al-Shehri et } \\
\text { al. [25] }\end{array}$ & $\begin{array}{l}\text { Comprehensive } \\
\text { comparison between } \\
\text { tactical and commercial } \\
\text { MANETs with } \\
\text { concerns to their } \\
\text { performance and design } \\
\text { characteristics. }\end{array}$ & $\begin{array}{l}\text { RPGM, } \\
\text { RWP, } \\
\text { Manhattan }\end{array}$ & $\begin{array}{l}\text { Mobile tactical } \\
\text { networks (focus } \\
\text { to military } \\
\text { communication). }\end{array}$ & $\begin{array}{l}\text { PDR. } \\
\text { Routing overhead. } \\
\text { Average } \\
\text { throughput. } \\
\text { E2E delay. }\end{array}$ & $\begin{array}{l}\text { Different radio } \\
\text { propagation and } \\
\text { mobility models needs } \\
\text { to be considered as } \\
\text { well as complex } \\
\text { security issue due to } \\
\text { the untrusted } 3^{\text {rd }} \text { party } \\
\text { suppliers of hardware } \\
\text { and software } \\
\text { components. }\end{array}$ \\
\hline Kim et al. [26] & $\begin{array}{l}\text { A novel routing } \\
\text { protocol for UAV } \\
\text { relayed } \\
\text { MANET, tactical } \\
\text { different features from } \\
\text { typical MANET was } \\
\text { shown and } 2 \text { scenarios } \\
\text { were proposed to be } \\
\text { used for network } \\
\text { congestion and link } \\
\text { breakage. }\end{array}$ & RPGM & $\begin{array}{l}\text { Tactical ad hoc } \\
\text { networks. }\end{array}$ & $\begin{array}{l}\text { PDR. } \\
\text { E2E delay. }\end{array}$ & $\begin{array}{l}\text { Corporation with } \\
\text { ground MANET } \\
\text { needs to be considered } \\
\text { to extend the current } \\
\text { network architecture. }\end{array}$ \\
\hline $\begin{array}{l}\text { Younes and } \\
\text { Albalawi [28] }\end{array}$ & $\begin{array}{l}\text { A proposed analytical } \\
\text { model for the link and } \\
\text { route lifetime in multi- } \\
\text { hop network and } \\
\text { comparison was made } \\
\text { between analytical and } \\
\text { simulation results. }\end{array}$ & RWP & $\begin{array}{l}\text { Mobile multi-hop } \\
\text { networks. }\end{array}$ & $\begin{array}{l}\text { PDF of link } \\
\text { lifetime. } \\
\text { PDF of route } \\
\text { lifetime. } \\
\text { Bounds (maximum } \\
\text { and minimum) of } \\
\text { the route lifetime. }\end{array}$ & $\begin{array}{l}\text { The increase the } \\
\text { transmission range, } \\
\text { the increase the } \\
\text { interference from the } \\
\text { neighbour nodes, } \\
\text { which led to the } \\
\text { decrement of network } \\
\text { throughput. }\end{array}$ \\
\hline
\end{tabular}

\section{Conclusion and future work}

The aim of this paper is to find a commonly used mobility model for disaster area scenarios towards the movement of the rescue teams. This paper reviewed the existing mobility models that have been used to simulate the movement of nodes in the disaster area scenario. However, there are some researches that are included into this study, whereas the existing mobility models are evaluated under tactical area networks, opportunistic network and multi-hop network. This is because, the environment of this network is closely relatable with the conditions of the tactical teams. Thus, this paper has discussed the existing mobility models that have been applied in the case of the disaster area which focusing on the movement of the rescue teams without considering the approach taken by the related papers. From the comparative analysis made through this paper, it can be concluded that the DA mobility model is an ideal mobility model that shows the realism of the node movement especially when adapted in the post-disaster area scenarios. However, there is still space for improvement in terms of the node's mobility considering suitable algorithms and routing protocols used in order to enhance the network performance of the rescue teams during their mission critical and SAR operations. The enhancement made can be focused in terms of energy consumption, network lifetime, overhead and NRL as the network efficiency can be one of the challenging issues in designing the mobility model, especially in an unfavourable situation such as the disaster area scenario where the fixed infrastructure network may unavailable due to damage.

Acknowledgment

This work was supported by the UniSZA/ MENTORMENTEE /2018/022 [R0046-R004] under the research of Performance Evaluation of Users Mobility Speed Over Mobile Cloud Computing.

\section{Conflicts of interest}

The authors have no conflicts of interest to declare.

\section{References}

[1] Aschenbruck N, Gerhards-padilla E, Martini P. Modeling mobility in disaster area scenarios. Performance Evaluation. 2009; 66(12):773-90.

[2] Mahiddin NA, Sarkar NI, Cusack B. An internet access solution: MANET routing and a gateway selection 
approach for disaster scenarios. The Review of Socionetwork Strategies. 2017; 11:47-64.

[3] Hoebeke J, Moerman I, Dhoedt B, Demeester P. An overview of mobile ad hoc networks: applications and challenges. Journal-Communications Network. 2004; 3(3):60-6.

[4] Mahiddin NA, Sarkar NI. An efficient gateway routing scheme for disaster recovery scenario. In international conference on information networking 2019 (pp. 2049). IEEE.

[5] Aschenbruck N, Gerhards-padilla E, Martini P. A survey on mobility models for performance analysis in tactical mobile networks. Journal of Telecommunications and Information Technology. 2008:54-61.

[6] Aschenbruck N, Ernst R, Gerhards-padilla E, Schwamborn M. Bonnmotion: a mobility scenario generation and analysis tool. In proceedings of the international ICST conference on simulation tools and techniques 2010 (pp. 1-10).

[7] Boldrini C, Conti M, Passarella A. Users mobility models for opportunistic networks: the role of phy sical locations. Proceddings of IEEE WRECOM. 2007.

[8] Nelson SC, Harris III AF, Kravets R. Event-driven, role-based mobility in disaster recovery networks. In proceedings of the second ACM workshop on challenged networks 2007 (pp. 27-34).

[9] Rollo M, Komenda A. Mobility model for tactical networks. In international conference on industrial applications of holonic and multi-agent systems 2009 (pp. 254-65). Springer, Berlin, Heidelberg.

[10] Papageorgiou C, Birkos K, Dagiuklas T, Kotsopoulos S. Simulating mission critical mobile ad hoc networks. In proceedings of the 4th ACM workshop on performance monitoring and measurement of heterogeneous wireless and wired networks 2009 (pp. 143-50).

[11] Pomportes S, Tomasik J, Vèque V. Ad hoc network in a disaster area: a composite mobility model and its evaluation. In the international conference on advanced technologies for communications 2010 (pp. 17-22). IEEE.

[12] Reina DG, Toral SL, Barrero F, Bessis N, Asimakopoulou E. Evaluation of ad hoc networks in disaster scenarios. In third international conference on intelligent networking and collaborative systems 2011 (pp. 759-64). IEEE.

[13] Raffelsberger C, Hellwagner H. Evaluation of MANET routing protocols in a realistic emergency response scenario. In proceedings of the 10th international workshop on intelligent solutions in embedded systems 2012 (pp. 88-92). IEEE.

[14] Conceição L, Curado M. Modelling mobility based on human behaviour in disaster areas. In international conference on wired/wireless internet communication 2013 (pp. 56-69). Springer, Berlin, Heidelberg.

[15] Martín-campillo A, Crowcroft J, Yoneki E, Martí R. Evaluating op portunistic networks in disaster scenarios. Journal of Network and Computer Applications. 2013; 36(2):870-80.
[16] Reina DG, Toral SL, Leon-coca JM, Barrero F, Bessis N, Asimakopoulou E. An evolutionary computational approach for optimizing broadcasting in disaster response scenarios. In international conference on innovative mobile and internet services in ubiquitous computing 2013 (pp. 94-100). IEEE.

[17] Reina DG, Toral SL, Barrero F, Bessis N, Asimakopoulou E. Modelling and assessing ad hoc networks in disaster scenarios. Journal of Ambient Intelligence and Humanized Computing. 2013; 4:5719.

[18] Ebenezer J. A mobility model for MANET in large scale disaster scenarios. In 17 th international conference on computer and information technology 2014 (pp. 59-64). IEEE.

[19] Reina DG, León-coca JM, Toral SL, Asimakopoulou E, Barrero F, et al. Multi-objective performance optimization of a probabilistic similarity/dissimilarity based broadcasting scheme for mobile ad hoc networks in disaster response scenarios. Soft Computing. 2014; 18:1745-56.

[20] Arbia DB, Alam MM, Attia R, Hamida EB. Behavior of wireless body-to-body networks routing strategies for public protection and disaster relief. In international conference on wireless and mobile computing, networking and communications 2015 (pp. 117-24). IEEE.

[21] Wang X, Li D, Zhang X, Tang H, Zhang G. A catastrophic intensity-based rescue mobility model for earthquake emergency rescue scenario. International Journal of Simulation--Systems, Science \& Technology. 2016; 17(38):1-6.

[22] Gondaliy a N, Atiquzzaman M. RTTM M: role based 3tier mobility model for evaluation of delay tolerant routing protocols in post disaster situation. In international conference on internet of things and big data 2016 (pp. 11-20). SCITEPRESS.

[23] Stute M, Maass M, Schons T, Hollick M. Reverse engineering human mobility in large-scale natural disasters. In proceedings of the ACM international conference on modelling, analysis and simulation of wireless and mobile systems 2017 (pp. 219-26).

[24] Sani AM, Newaz SS, Wani SM, Wan AT, Jahan S. TCP performance evaluation under manet routing protocols in disaster recovery scenario. In international conference on advances in electrical engineering 2017 (pp. 389-94). IEEE.

[25] Al-shehri SM, Loskot P, Numanoğlu T, Mert M. Comparing tactical and commercial MANETs design strategies and performance evaluations. In military communications conference 2017 (pp. 599-604). IEEE.

[26] Kim BS, Kim KI, Roh B, Choi H. A new routing protocol for UAV relayed tactical mobile ad hoc networks. In wireless telecommunications symposium 2018 (pp. 1-4). IEEE.

[27] Kim N, Na W, Cho S. Dual-channel-based mobile ad hoc network routing technique for indoor disaster environment. IEEE Access. 2020; 8:126713-24. 
[28] Younes OS, Albalawi UA. Analy sis of route stability in mobile multihop networks under random waypoint mobility. IEEE Access. 2020; 8:168121-36.

[29] Sakano T, Fadlullah ZM, Ngo T, Nishiyama H, Nakazawa M, Adachi F, et al. Disaster-resilient networking: a new vision based on movable and deployable resource units. IEEE Network. 2013; 27(4):40-6.

[30] Sakano T, Kotabe S, Komukai T. Overview of movable and deployable ICT resource unit architecture. NTT Technical Review. 2015; 13(5):1-6.

[31] Sakano T, Kotabe S, Komukai T, Kumagai T, Shimizu Y, Takahara A, et al. Bringing movable and deployable networks to disaster areas: development and field test of MDRU. IEEE Network. 2016; 30(1):86-91.

[32] Pervez F, Qadir J, Khalil M, Yaqoob T, Ashraf U, Younis S. Wireless technologies for emergency response: a comprehensive review and some guidelines. IEEE Access. 2018; 6:71814-38.

[33] Höchst J, Baumgärtner L, Kuntke F, Penning A, Sterz A, Freisleben B. Lora-based device-to-device smartphone communication for crisis scenarios. In proceedings of the international conference on information systems for crisis response and management 2020.

[34] Nik WN, Mohamad Z, Zakaria AH, Azlan AA. iBeeHOME: an intelligent stingless honey beehives monitoring tool based on TOPSIS method by implementing LoRaWan-a preliminary study. In computational science and technology 2020 (pp. 66976). Springer, Singapore.

[35] Sciullo L, Trotta A, Di FM. Design and performance evaluation of a LoRa-based mobile emergency management system. Ad Hoc Networks. 2020.

[36] Khan MA, Safi A, Qureshi IM, Khan IU. Flying ad-hoc networks (FANETs): a review of communication architectures, and routing protocols. In first international conference on latest trends in electrical engineering and computing technologies 2017 (pp. 19). IEEE.

[37] Bongsu RHR., Mohammed A., Mohamed MA, Recent trends in channel assignment algorithms for multi-radio multi-channel in wireless mesh network. International Journal of Recent Technology and Engineering. 2019; 7(5S4):656-9. IJRTE.

[38] Molla DM, Badis H, Desta AA, George L, Berbineau M. SDR-based reliable and resilient wireless network for disaster rescue operations. In international conference on information and communication technologies for disaster management 2019 (pp. 1-7). IEEE.

[39] Solpico D, Tan MI, Manalansan EJ, Zagala FA, Leceta JA, Lanuza DF, et al. Application of the V-HUB standard using LoRa beacons, mobile cloud, uavs, and $\mathrm{dtn}$ for disaster-resilient communications. In IEEE global humanitarian technology conference 2019 (pp. 1-8). IEEE.

[40] Qiu J, Grace D, Ding G, Zakaria MD, Wu Q. Airground heterogeneous networks for $5 \mathrm{G}$ and beyond via integrating high and low altitude platforms. IEEE Wireless Communications. 2019; 26(6):140-8.

[41] Manaseer S, Alawneh A. A new mobility model for Ad Hoc networks in disaster recovery areas. International Journal of Online Engineering. 2017; 13(6):113-20.

[42] Camp T, Boleng J, Davies V. A survey of mobility models for ad hoc network research. Wireless Communications and Mobile Computing. 2002; 2(5):483-502.

[43] Rhee I, Shin M, Hong S, Lee K, Kim SJ, Chong S. On the levy-walk nature of human mobility. IEEE/ACM Transactions on Networking. 2011; 19(3):630-43.

[44] Kumar S, Sharma SC, Suman B. Mobility metrics based classification \& analysis of mobility model for tactical network. International Journal of NextGeneration Networks. 2010; 2(3):39-51.

[45] Patle VK, Kumar S. Evaluation of mobility model with MANET routing protocols. International Journal of Computer Applications. 2016; 152(8):8-12.

[46] https://www.isi.edu/nsnam/ns/. Accessed 10 April 2021.

[47] https://www.nsnam.org/. Accessed 10 April 2021.

[48] Dorathy I, Chandrasekaran M. Simulation tools for mobile ad hoc networks: a survey. Journal of Applied Research and Technology. 2018; 16(5):437-45.

[49] https://www.scalable-networks.com/products/qualnetnetwork-simulation-software-tool/. Accessed 10 April 2021.

[50] https://omnetpp.org/intro/. Accessed 10 April 2021.

[51] Keränen A, Ott J, Kärkkäinen T. The ONE simulator for DTN protocol evaluation. In proceedings of the international conference on simulation tools and techniques 2009 (pp. 1-10).

[52] https://www.tetcos.com/. Accessed 20 February 2021.

[53] http://jist.ece.cornell.edu/. Accessed 20 February 2021.

[54] https://www.physiome.org/jsim/. Accessed 20 February 2021.

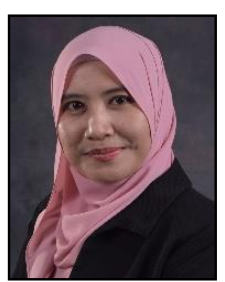

Nor Aida Mahiddin received the B.S. Degree in Information Technology from National University of Malaysia, the Master's Degree in Computer Science Major in Distributed Computing and Ph.D. degrees in Computer and Information Sciences from Auckland University of Technology, New Zealand. Dr. Nor Aida is currently a lecturer at Faculty of Informatics and Computing, University Sultan Zainal Abidin, Malaysia. She is the author of several papers in peerreviewed journals and conferences proceeding. She is currently a member of the Institute of Electrical and Electronics Engineers (IEEE), Internet Society and The Society of Digital Information and Wireless Communications (SDIWC). Her research interests include Network Design, Modelling And Performance Evaluation, Wireless Communication Networks, Disaster Resilient Network Design, Optimization Of Gateway Congestion Control, Ad Hoc And Sensor Networks and Wireless Mesh and Routing Protocols.

Email: aidamahiddin @unisza.edu.my 


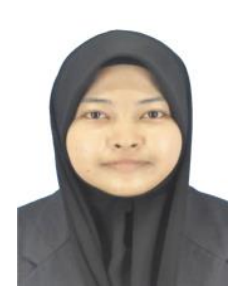

Fatin Fazain Mohd Affandi is a Computer Science's student, born and brought up in Besut, Terengganu, Malaysia. She did her Bachelors of Computer Science, Major in Network Security in the year 2019. Her area of interest is in Network and Security. She is a PG student currently in the course named "Masters in Computer Science" at Universiti Sultan Zainal Abidin (UniSZA), Terengganu, Malaysia.

Email: fatinfazain@gmail.com

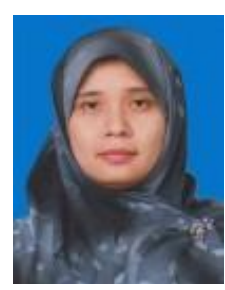

Zarina Mohamad was born in Kuala Terengganu, Terengganu, Malaysia in 1972. She received her B.S and M.S degrees in computer science in 2000 and 2004, respectively. In 2013 she received her Ph.D from Universiti Tun Hussien Onn Malay sia. She is currently a senior lecturer in the Faculty of Informatics and Computing, Universiti Sultan Zainal Abidin (UniSZA), Terengganu, Malay sia. Her research interests are Distributed Database, Data Grid, Distributed Systems, Cloud Computing and Optimization.

Email: zarina@unisza.edu.my

Appendix I

\begin{tabular}{|c|c|c|}
\hline S.No. & Abbreviation & Description \\
\hline 1. & AODV & Ad-Hoc on-demand Distance Vector \\
\hline 2. & AODVv2 & AODV Version 2 \\
\hline 3. & AOMDV & $\begin{array}{l}\text { Ad-hoc On-demand Multipath Distance } \\
\text { Vector }\end{array}$ \\
\hline 4. & BATMAN & $\begin{array}{l}\text { Better Approach to Mobile Ad-hoc } \\
\text { Network }\end{array}$ \\
\hline 5. & BLE & Bluetooth Low Energy \\
\hline 6. & CBR & Constant Bit Rate \\
\hline 7. & $\mathrm{CCS}$ & Casualties Clearing Station \\
\hline 8. & CI & Catastrophic intensity \\
\hline 9. & CIBRMM & $\begin{array}{l}\text { Catastrophic Intensity-based Rescue } \\
\text { Mobility Model }\end{array}$ \\
\hline 10. & CMM & Community-based Mobility Model \\
\hline 11. & CoM & Composite Mobility \\
\hline 12. & CTA & Casual Treatment Area \\
\hline 13. & DA & Disaster Area \\
\hline 14. & DAWNs & Disaster Area Wireless Networks \\
\hline 15. & DCR & Dual-Channel-based Routing \\
\hline 16. & $\mathrm{DD}$ & Directed Diffusion \\
\hline 17. & DSDV & Destination-Sequenced Distance-Vector \\
\hline 18. & DSR & Dynamic Source Routing \\
\hline 19. & DTN & Delay Tolerant Network \\
\hline 20. & DYMO & Dynamic MANET on-demand \\
\hline 21. & E2E & End-to-End \\
\hline 22. & EBR & Encounter Based Routing \\
\hline 23. & ECS & Emergency Communication System \\
\hline 24. & ERM & Event and Role-based Mobility \\
\hline 25. & ERMM & Event and Role-based Mobility Model \\
\hline 26. & FANETs & Flying Ad-Hoc Networks \\
\hline 27. & FMNs & Flying Mesh Networks \\
\hline 28. & FWA & Fixed Wireless Access \\
\hline 29. & GM & Gauss-Markov \\
\hline 30. & GloMoSim & $\begin{array}{l}\text { Global Mobile Information System } \\
\text { Simulator }\end{array}$ \\
\hline 31. & GPS & Global Positioning System \\
\hline 32. & GPSR & Greedy Parameter Stateless Routing \\
\hline 33. & GSM & Global System for Mobile \\
\hline 34. & GUI & Graphical User Interface \\
\hline 35. & HAPs & High-Altitude Platforms \\
\hline 36. & HBDA & Human Behavior for Disaster Area \\
\hline
\end{tabular}

873

\begin{tabular}{|c|c|c|}
\hline 37. & HCMM & $\begin{array}{l}\text { Home-cell Community-based Mobility } \\
\text { Model }\end{array}$ \\
\hline 38. & HUMO & Human Obstacle Mobility \\
\hline 39. & $\mathrm{IL}$ & Incident Location \\
\hline 40. & IoT & Internet of Things \\
\hline 41. & JiST & Java in Simulation Time \\
\hline 42. & JSim & Java-based Simulator \\
\hline 43. & LAPs & Low-Altitude Platforms \\
\hline 44. & LAN & Local Area Network \\
\hline 45. & LoRa & Long Range-based \\
\hline 46. & LoRaWAN & Low Power Wide Area Network \\
\hline 47. & LSDMM & Large Scale Disaster Mobility Model \\
\hline 48. & MANET & Mobile Ad-Hoc Network \\
\hline 49. & MCMM & Mission Critical Mobility Model \\
\hline 50. & MDRUs & $\begin{array}{l}\text { Movable and Deployable Resource } \\
\text { Units }\end{array}$ \\
\hline 51. & MML & Mathematical Modelling Language \\
\hline 52. & MRMC & Multi-Radio Multi-Channel \\
\hline 53. & ND & Natural Disaster \\
\hline 54. & NetSim & Network Simulator \\
\hline 55. & NRL & Normalized Routing Load \\
\hline 56. & NS-2 & Network Simulator 2 \\
\hline 57. & NS-3 & Network Simulator 3 \\
\hline 58. & OLS & Opening Lifeline Stage \\
\hline 59. & OLSR & Optimized Link State Routing \\
\hline 60. & OLSRv2 & OLSR Version 2 \\
\hline 61. & $\mathrm{OM}$ & Obstacle Mobility \\
\hline 62. & OMNeT++ & $\begin{array}{l}\text { Objective Modular NETwork Testbed } \\
\text { in C++ }\end{array}$ \\
\hline 63. & ONE & Opportunistic Networking Environment \\
\hline 64. & OPNet & Optimized Network Engineering tool \\
\hline 65. & PDF & Packet Delivery Fraction \\
\hline 66. & PDR & Packet delivery ratio \\
\hline 67. & PPDR & Public Protection and Disaster Relief \\
\hline 68. & PRR & Packet tmm \\
\hline 69. & PWT & Patient Waiting for Treatment \\
\hline 70. & QoS & Quality of Service \\
\hline 71. & R\&D & Research and Development \\
\hline 72. & RANs & Radio Access Networks \\
\hline 73. & RPGM & Reference Point Group Mobility \\
\hline 74. & RW & Random Walk \\
\hline 75. & RWP & Random Waypoint \\
\hline 76. & RWPA & Random Waypoint with Attraction \\
\hline 77. & RTTMM & Role-based 3-Tier Mobility Model \\
\hline 78. & SAR & Search and Rescue \\
\hline 79. & SDR & Software Defined Radio \\
\hline 80. & SRB & Saved Re-Broadcast \\
\hline 81. & SRS & Spreading Rescue Stage \\
\hline 82. & SWANS & Scalable Wireless Network Simulator \\
\hline 83. & TBs & Throw Boxes \\
\hline 84. & $\mathrm{Tcl}$ & Tool Command Language \\
\hline 85. & TCP & Transmission Control Protocol \\
\hline 86. & TNMM & Tactical Networks Mobility Model \\
\hline 87. & TMM & Traditional Mobility Model \\
\hline 88. & TOC & Technical Operational Command \\
\hline 89. & $\mathrm{TZ}$ & Transport Zone \\
\hline 90. & UAV & Unmanned Aerial Vehicle \\
\hline 91. & V-HUB & Vehicle Hub \\
\hline 92. & $\mathrm{~V} 2 \mathrm{X}$ & Vehicle-to-Everything \\
\hline 93. & WAN & Wide Area Network \\
\hline 94. & WBAN & Wireless Body Area Network \\
\hline 95. & WiFi & Wireless Fibre \\
\hline 96. & WSNs & Wireless Sensor Networks \\
\hline 97. & WMN & Wireless Mesh Network \\
\hline 98. & WMHN & Wireless Multi-Hop Network \\
\hline 99. & ZRP & Zone Routing Protocol \\
\hline
\end{tabular}

